\title{
Safety regulation of gel electrolytes in electrochemical energy storage devices
}

\author{
Dan $\mathrm{Yu}^{1}$, Xinyue $\mathrm{Li}^{1,2}$ and Jialiang $\mathrm{Xu}^{1,2^{*}}$
}

\begin{abstract}
Electrochemical energy storage devices, such as lithium ion batteries (LIBs), supercapacitors and fuel cells, have been vigorously developed and widely researched in past decades. However, their safety issues have appealed immense attention. Gel electrolytes (GEs), with a special state in-between liquid and solid electrolytes, are considered as the most promising candidates in electrochemical energy storage because of their high safety and stability. This review summarized the recent progresses made in the application of GEs in the safety regulation of the electrochemical energy storage devices. Special attention was paid to the gel polymer electrolytes, the organic low molecule-mass GEs, as well as the fumed silica-based and siloxane-based GEs. Finally, the current challenges and future directions were proposed in terms of the development of GEs.
\end{abstract}

Keywords: electrochemical energy storage devices, safety regulation, gel electrolytes, gel polymer electrolytes, organic low molecule-mass gel electrolytes

\section{INTRODUCTION}

With the dramatic advancement of science and technology, electronic instruments and equipments, such as mobile phones, laptops and electric vehicles, have been rapidly developed, which leads to the higher and higher demand for power supplies. Current energy storage technologies mainly include mechanical energy storage, chemical energy storage, electromagnetic energy storage and phase change energy storage [1-3]. Electrochemical energy storage devices, such as lithium ion batteries (LIBs), lead acid batteries (LABs) and supercapacitors, have become the main supply sources for these electronic equipments due to their greatly improved energy density, power density and cycle lifespan in the past decades [4-
8]. These electrochemical energy storage devices are so indispensable in our daily life that their safety performance and service life are important criteria for consumers' reference. In this context, there still remain safety issues that have to be taken into great consideration $[9,10]$. Usually, due to operational errors or the bad performance of some devices, there are many risks such as thermal runaway because of overcharge and internal short circuit-caused lithium dendrite formation, etc. The possibility of fires, explosion and even casualties will increase greatly if these risks remain uncontrolled.

As one of the main components of electrochemical energy storage devices, the electrolytes are of critical importance to achieve the electrochemical performance of them. There are three major types of electrolytes: solid electrolytes (SEs), liquid electrolytes (LEs) and gel electrolytes (GEs) [11]. LEs are favored for their high ionic conductivity $\left(10^{-3}-10^{-2} \mathrm{~S} \mathrm{~cm}^{-1}\right)$ and good/stable contact with electrodes. However, with the LIBs coming into our daily life, their safety issues cannot be ignored. Organic LEs are the most common GEs, of which the high risk of leakage and even combustion are the main safety issues. Lithium dendrite growth is also one of the fundamental problems affecting the safety and stability of LIBs [12]. During the repeated deposition and precipitation of lithium ions, lithium dendrites are easily grown on the surface of the metal lithium negative electrode. The formation of lithium dendrites destroys the stability of the interface between electrode and electrolyte. More dangerously, the dendrites will pierce the separator and lead to the short circuit inside lithium batteries. Moreover, the thermal runaway caused by it is highly likely to cause a fire or an explosion. SEs, which address both the leakage and dendrite growth problems, are considered as a useful

\footnotetext{
${ }^{1}$ School of Chemical Engineering and Technology, Tianjin University, Tianjin 300350, China

${ }^{2}$ School of Materials Science and Engineering, National Institute for Advanced Materials, Nankai University, Tianjin 300350, China

*Corresponding author (email: jialiang.xu@nankai.edu.cn)
} 
alternative. However, SEs also encounter several challenges: (1) low ionic conductivity $\left(10^{-8}-10^{-4} \mathrm{~S} \mathrm{~cm}^{-1}\right),(2)$ high interfacial resistance, (3) the volume change during the charging and discharging process, resulting in the separation of the interface, (4) increased quality energy density and volume energy density. In this context, GEs exhibit unique superiority due to their state: in-between all-solid state and liquid state. GEs feature high ion conductivity and good interfacial properties due to LEs, and non-leakage and good mechanical properties due to SEs. GEs can also contribute to suppressing the dendrite growth [13-18]. As a result, GEs have been becoming more and more promising $[19,20]$.

This paper reviews the safety regulation of electrochemical storage devices by taking advantage of GEs. The content includes three sections: polymer GEs, organic low molecule-mass GEs as well as the fumed-based silica and siloxane-based GEs. The applications of different kinds of GEs in various electrochemical energy storage devices have been summarized in Table 1. The current state of art for GEs applied in the field of electrochemical storage devices has been summarized, and their possible direction for development in the future has been outlooked.

\section{GEL POLYMER ELECTROLYTES (GPES)}

The electrolyte is a critical component in the energy storage system. With various hazards posed by organic LEs, the researchers have been looking for alternatives, such as polymer electrolytes, inorganic ion conductor electrolytes and ionic LEs (ILEs) [21]. The investigation on the polymer electrolytes was firstly carried out in the 1980s [22], and they have evolved into different types, including dry solid polymer electrolytes, GEs and composite electrolytes [23]. Dry solid polymer electrolytes usually have low ionic conductivity and high degree of crystallization, which are the main factors restricting their development and application on a large scale [24,25]. Based on this, a type of gel polymer electrolytes (GPEs) was proposed to improve the ionic conductivity and lower their crystallization. The GPEs usually consist of polymer, plasticizer (organic solvent) and electrolyte salt. The polymer works as the matrix to fix the solvent. When the polymer swells and entraps organic solvents, the gel is formed $[26,27]$. Therefore, the GEs can always have both diffusion transportability and cohesiveness, special features of LEs and SEs, respectively.

\section{Traditional polymer skeleton-based GPEs}

It is known that the base of GPEs is polymer framework [28]. Therefore, the performance of GPEs depends highly
Table 1 The application of different kinds of GEs in different electrochemical energy storage devices

\begin{tabular}{ccc}
\hline Energy storage devices & GEs \\
\hline Lithium-type & batteries & Inorganic type \\
Organic polymer type \\
Organic low mass type \\
Colloid-based silica \\
Lead-acid batteries & $\begin{array}{c}\text { Fumed-based silica } \\
\text { Polysiloxane-based material }\end{array}$ \\
& Sodium-sulfur & Inorganic type \\
& batteries & Organic polymer type \\
& Organic low mass type \\
& Flow batteries & Electrolyte in liquid state \\
\hline Supercapacitor & Inorganic type \\
& Electric double- & Organic polymer type \\
& Organic low mass type \\
& Pseudo capacitors & Inorganic type \\
& Organic polymer type \\
& Organic low mass type \\
\hline
\end{tabular}

on the nature of polymer host. Usually, the definition of GPE depends on whether the state of the integral electrolyte system is in gel, because the polymer hosts cannot form into electrolytes alone. Herein, the recent progress of GPEs is summarized based on some traditional polymer hosts: polyethylene oxide (PEO), poly(methyl methacrylate) (PMMA), polyacrylonitrile (PAN) and poly (vinylidene fluoride) (PVDF).

\section{PEO}

PEO is the earliest and the most widely used polymer in GPE system [22], which was selected as the most popular polymer matrix for its high salt complexation and good dimensional stability. Li et al. [29] prepared a GPE using $\mathrm{PEO}$ as the polymer host through in situ polymerization. Ethoxylated trimethylolpropane triacrylate (ETPTA) ionomer and LE were mixed and then exposed to the UV light to form a network crosslinked GE [30] (Fig. 1). Inside of the obtained GPE, the LE was framed into the solidified skeleton of the polymer. Therefore, the leakage of organic liquid was avoided, so that a certain degree of safety could be ensured. In addition, the thermogravimetric analysis (TGA) and differential scanning calorimetry (DSC) showed that GPE did not decompose until $200^{\circ} \mathrm{C}$ (Fig. 1b), indicating a good thermal stability. On the other hand, through the comparison of combustion experiment, the GPE owned better flame retarding (Fig. 1c). All of these points are beneficial to improving the safety of the relevant battery. Dagousset et al. [31] reported a binary mixture of $\gamma$-butyrolactone (GBL) and 1-ethyl-3-methylimidazolium bis(trifluoromethane sulfo- 

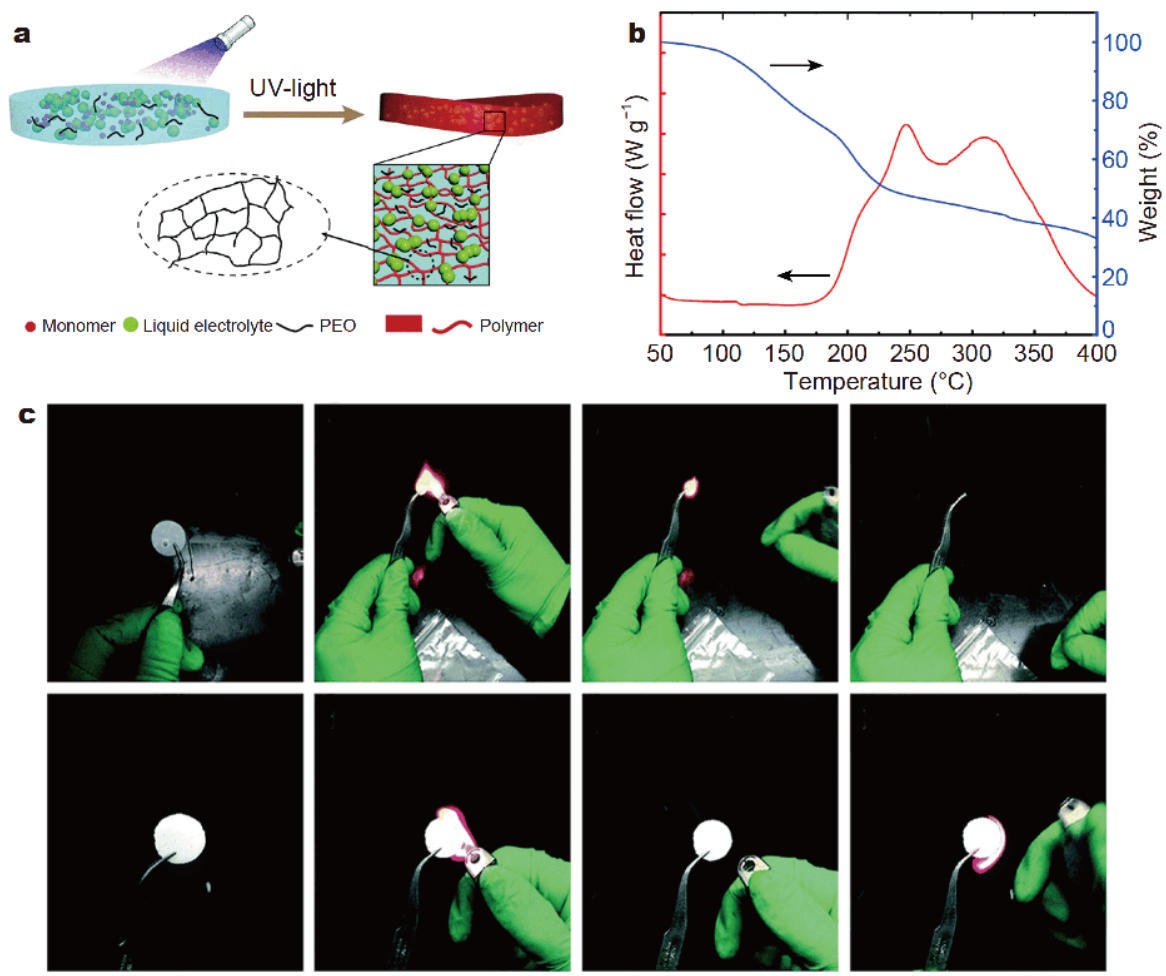

Figure 1 (a) The preparation process and the illustration of the GPE membrane. (b) TGA and DSC curves of GPE. (c) The combustion test of commercialized separator (top) and GPE membrane (bottom). Reproduced with permission from Ref. [29]. Copyright 2017, the Royal Society of Chemistry.

nyl) imide (EMITFSI)-based ionic liquid (IL). When used as an electrolyte for supercapacitors, the system can operate over a very wide temperature range $\left(-50-100^{\circ} \mathrm{C}\right)$ and achieve a high ionic conductivity. Later, Dagousset et al. [32] combined a semi-penetrating polymer network based on PEO and the non-crosslinking nitrile butadiene rubber (NBR) with the EMITFSI/GBL so as to synthesize a flexible and self-standing GPE as the electrolyte for supercapacitors. The self-standing GPE not only ensured a broad operating temperature range but also possessed large electrochemical stability windows of $3.2-3.6 \mathrm{~V}$ at $20^{\circ} \mathrm{C}$ and $2.1-2.5 \mathrm{~V}$ at $100^{\circ} \mathrm{C}$. Moreover, during the period of floating at $100^{\circ} \mathrm{C}$, the self-standing GPE manifested a high stability. It is a great potential for the safety improvement of GPE in electrochemical storage devices.

\section{PMMA}

Lijima et al. [33] firstly used PMMA as polymer matrix of GPE in 1985. The carbonyl group contained in PMMA can strongly interact with the oxygen in a carbonate solvent, so that a large amount of electrolyte can be absorbed. The solid electrolyte interface (SEI) film which was formed between the PMMA and metal lithium had a stable structure with small impedance, thereby improving the interface stability of electrode materials.

Zhao et al. [34] reported a kind of GPE based on the PMMA matrix composited with methacrylisobutyl-polyhedral oligomeric silsequioxane (MA-POSS) (Fig. 2a). This GPE obtained by the phase inversion method owned a significant porosity, which was able to absorb more LEs, and correspondingly improving the conductivity. On the one hand, the MA-POSS could enhance the mechanical property, and reduce the flammability and heat release during the combustion of composite material. Meanwhile, the MA-POSS could be more compatible with PMMA and the plasticizer for the existence of organic side chain (MA) [35-38]. Particularly, GPE exhibited optimized electrochemical performance when the mass ratio of MA-POSS was $10 \mathrm{wt} \%$ (Fig. 2b, c). Both electrolyte uptake and porosity reached the maximum point (Fig. 2b), and the electrochemical impedance spectra (EIS) curves demonstrated the resistance and the highest conductivity (Fig. 2c). Moreover, the pore structure in the GPE could be impacted. When the content of MA-POSS exceeded $10 \mathrm{wt} \%$, aggregation was highly likely to occur, which might result in a sharp drop in electrochemical 
a

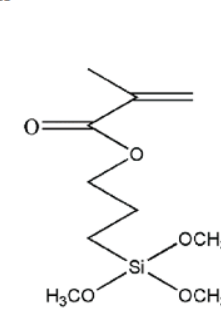

d

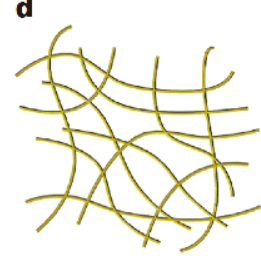

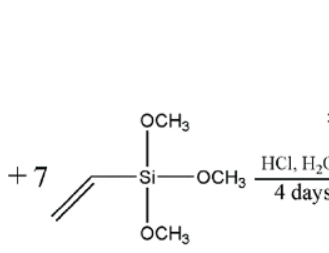

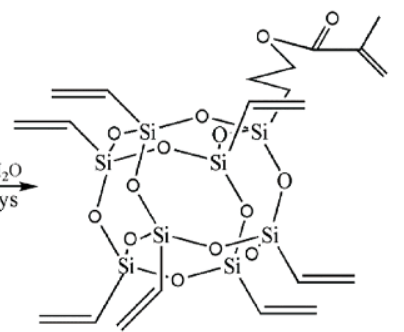

$\mathbf{e}$

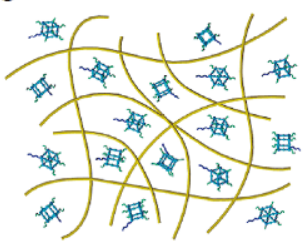

PMMA chains

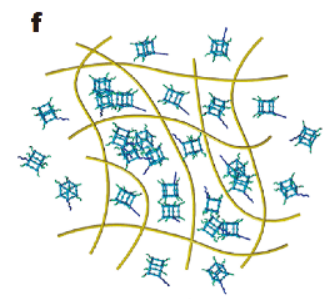

MA-POSS
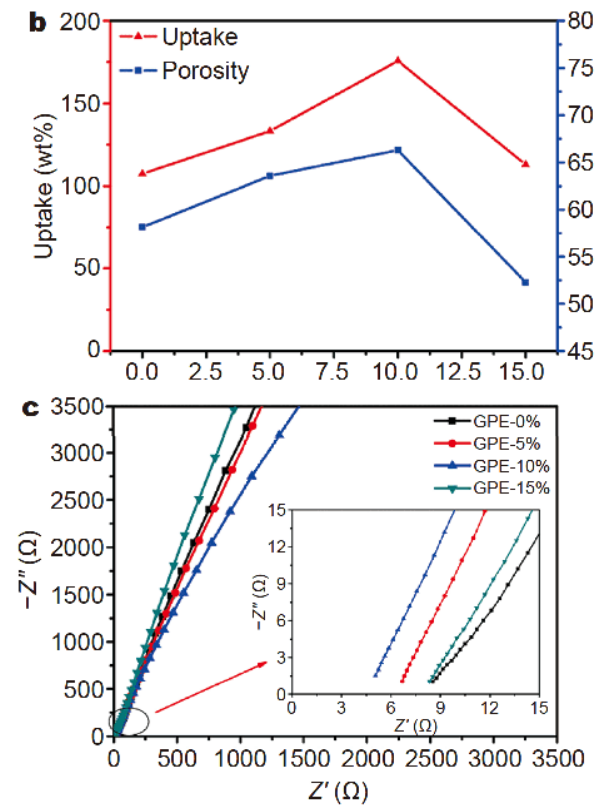

Figure 2 (a) The synthetic route of MA-POSS. (b) Electrolyte uptake and porosity of GPEs with different portions of MA-POSS. (c) EIS curves of the typical GPEs at room temperature (RT). (d-f) The different states of PMMA and MA-POSS with different portions of MA-POSS (d: GPE-0\%; e: GPE10\%; f: GPE-15\%). Reproduced with permission from Ref. [34]. Copyright 2018, Elsevier.

performance (Fig. 2d-f). Liu et al. [39] later introduced the POSS nanoparticles into the PMMA matrix by polymerization (Fig. 3a). This approach overcame the poor dispersion of POSS in the PMMA matrix, which was superior to the previously reported physical mixtures (Fig. 3b-e). Similarly, this kind of GPE also had the best electrochemical performance when the content of POSS was $10 \mathrm{wt} \%$ and the excellent thermal performance of the GPE could assure the safety of electrochemical storage devices.

\section{PAN}

PAN is widely used in electrolytes because of its simple synthesis, high chemical stability and non-flammability [40-44]. Feuillade et al. [28] studied the properties of the PAN as polymer matrix as early as 1975 . However, due to the presence of a strong polar cyanide $(-\mathrm{CN})$ group on the PAN chain, the polymer easily formed a relatively severe interface passivation with the lithium electrode, resulting in an increase in interface resistance. He et al. [45] put forward a PAN/organic montmorillonite (OMMT) membrane system, in which the $\mathrm{LiPF}_{6} \mathrm{LE}$ swelled and entirely formed a kind of GPE for LIB. OMMT modified by a hydrophobic group of hexadecyl trimethyl ammonium bromide via ion exchange was doped into the PAN, and the change in porosity was clearly observed. When the ratio of PAN/OMMT was
5:95 (wt\%/wt\%), an optimal distribution of pores was achieved. In addition, the well-dispersed OMMT strengthened the interaction between PAN and OMMT, making the electrolyte membrane structure denser, which not only improved the thermal stability of PAN/OMMT, but also effectively inhibited the growth of lithium dendrites.

Liu et al. [46] also introduced the POSS nanoparticles into the PAN matrix by polymerization and synthesized a $\mathrm{P}$ (AN-POSS) membrane and immersed the membrane into LE to get the final GPE. The participation of POSS affected the polymerization sequence of AN monomers, which weakened the interaction of cyanide groups $(-\mathrm{CN})$ on the AN chain. The molecular chains were more likely to rotate around the single bond, and the segment movement was more likely to occur. Thus, the macromolecular chain was more flexible, and a larger amorphous area was produced. The inhibition of charge carrier transfer in the crystal region was reduced, and accordingly, the ion conductivity, lithium ion migration number, and the interface stability of GPE were improved. TGA measurements showed that, although the initial decomposition temperature of $\mathrm{P}(\mathrm{AN}-\mathrm{POSS})$ was lower than that of PAN, the overall mass loss of the former was more gradual, and the quality retention rate of $\mathrm{P}(\mathrm{AN}$ POSS) was $57.1 \%$ when it was heated to $500^{\circ} \mathrm{C}$, higher than that of PAN (52.8\%). Remarkably, the decomposi- 

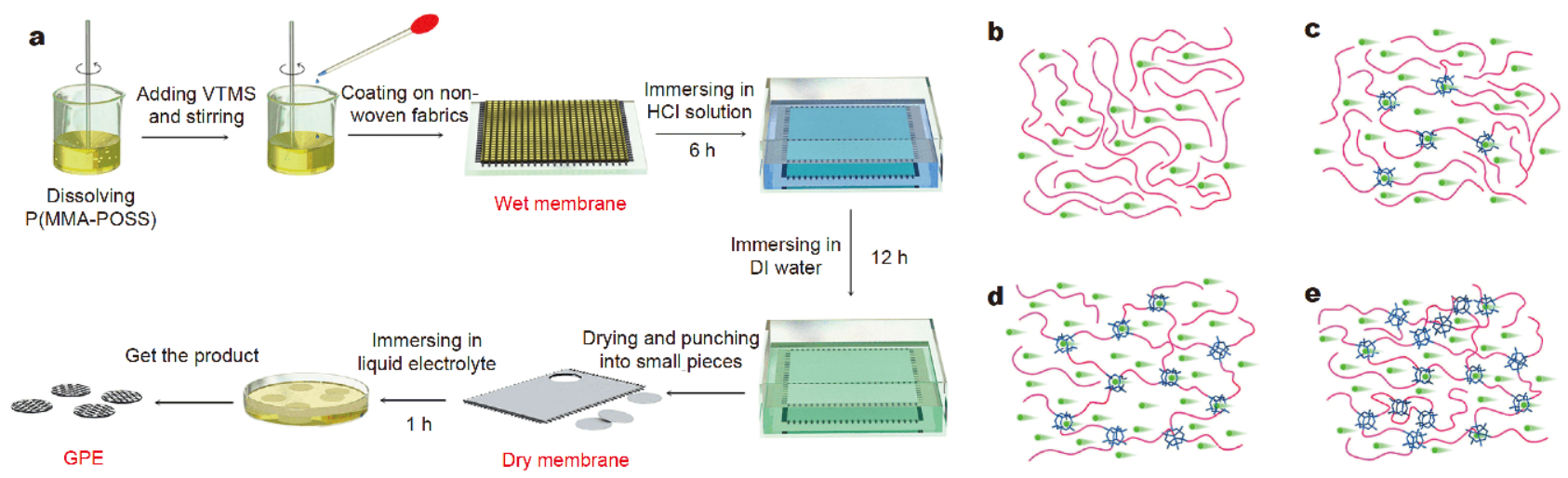

Figure 3 (a) The preparation process illustration of PMMA and P(MMA-POSS) GPEs. Models of lithium ions conduction in GPEs: (b) GPE-0\%, (c) GPE-5\%, (d) GPE-10\% and (e) GPE-15\%. Reproduced with permission from Ref. [39]. Copyright 2018, Elsevier.

tion temperature of $\mathrm{P}(\mathrm{AN}-\mathrm{POSS})$ exceeded $234^{\circ} \mathrm{C}$, and such a high thermal stability guaranteed a high degree of safety.

Since copolymerization can change the interaction of -CN groups, Huang et al. [47] synthesized a copolymer of acrylonitrile and maleic anhydride (P(AN-MAH)) and prepared a series of GPEs based on this copolymer matrix through phase inversion (Fig. 4a). The pull-in of copolymer monomers MAH could make a better compatibility with electrode because its negative groups broke the interaction between the $-\mathrm{CN}$ groups on the chain. Meanwhile, the space barrier created by the bulk may weaken the electrostatic interaction between the $-\mathrm{CN}$ group and electrode. The performance of copolymer membrane differed when the mass ratio of AN:MAN was designed as $1 / 0,6 / 1,4 / 1$, and 2/1. Experiments showed that when the mass ratio was $4 / 1$, the pore structure and thermal stability of the copolymer film were optimized. Moreover, the GPE based on the copolymer film was used in a Li/ GPE/LFP battery for the performance test. Similarly, when the mass ratio was $4 / 1$, the initial charge and discharge capacity at different magnifications and cycle performance of the battery were all optimal, indicating that the copolymer film imparted excellent overall properties to the corresponding GPE (Fig. 4b-e).

\section{PVDF}

The excellent electrical and chemical properties of PVDF guarantee its suitability as a polymer GE material. The higher dielectric constant of PVDF [48-51] is beneficial to promoting the dissolution of lithium salts. The low glass transition temperature is also beneficial to the dis-
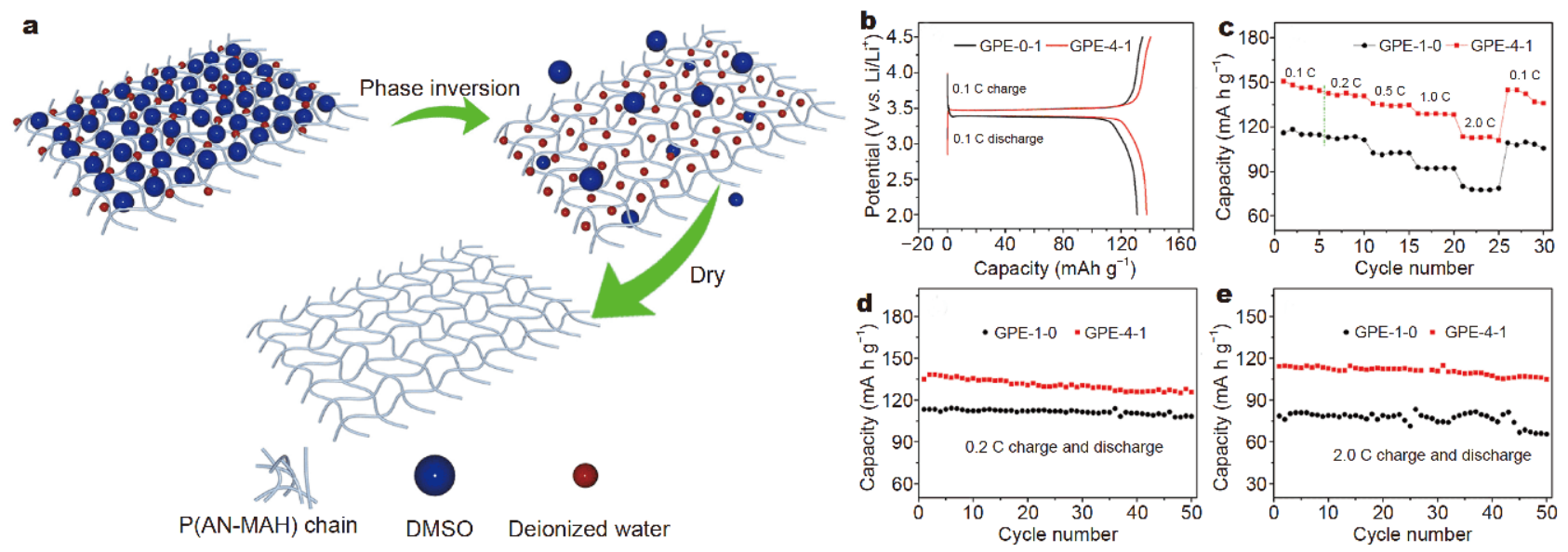

Figure 4 (a) The schematic diagram of the phase inversion, (b) the initial charge/discharge curves, (c) C-rate behavior, and (d, e) the cycle performances of $\mathrm{Li} / \mathrm{GPE} / \mathrm{LiFePO}_{4}$ battery using the GPE-1-0 and GPE-4-1, respectively. Reproduced with permission from Ref. [47]. Copyright 2018, Elsevier. 
sociation of the lithium salt. In addition, the fluorine atom on the side chain of PVDF has a strong ability to absorb electricity, endowing PVDF with strong resistance to electrochemical oxidation.

Due to the high crystallinity of PVDF (65\%-78\%), its electrolyte retention and ionic conductivity are both poor. Zuo et al. [52] blended ethyl cellulose (EC) to PVDF with different weight ratios to prepare a membrane by immersion precipitation phase inversion, and the membrane was further soaked into LE to obtain the GPE. The EC is a low-cost and environment-friendly amorphous polymer which can be conducive to decreasing the crystallinity of PVDF. Cellulosic materials, as a good substitute for petroleum-based materials, have inspired researchers to develop diverse electrochemical energy storage devices with an expectation of improving certain performances $[53,54]$. Hydroxyethyl cellulose (HEC) was first applied into the LIB as the matrix of GPE. The HEC membrane was thermally stable up to $280^{\circ} \mathrm{C}$ [55]. However, the GPE of dense HEC type had a relatively poor mechanical property, leading to processing difficulties [56,57]. Therefore, through an elaborate design, Zhang et al. [56] reported a sandwich PVDF/HEC/PVDF GPE for LIB (Fig. 5), which greatly improved the mechanical strength compared with pure HEC. The HEC in the intermediate layer was able to effectively avoid micro short circuit, and therefore improve the safety performance of large-capacity batteries, such as electronic vehicles. In addition, the PVDF made by electrospinning simplified the preparation technology. The composite of PVDF and HEC had a high decomposition temperature of over $290^{\circ} \mathrm{C}$, both of which were fire-retarding.

\section{Responsive GPEs}

Stimulus-responsive polymers have received widespread attention from academic and industry circles because of their ability to respond to a wide variety of external stimuli, such as the $\mathrm{pH}$, light, temperature, voltage, oxidizing and reducing agents and gases. Stimulusresponsive polymers can be used as smart materials in many fields as they are usually capable of realizing stimulus-induced conformational changes, reversible solubility changes and reversible changes between selfassembly and polymer micelles vesicles [58-60].

Temperature or heat is the most common and widely used external stimulus. Most temperature-sensitive polymers exhibit a critical solution temperature, undergoing a reversible phase transition upon thermal induction [61]. It's inevitable that security issues are involved for all kinds of electrochemical energy devices. In spite
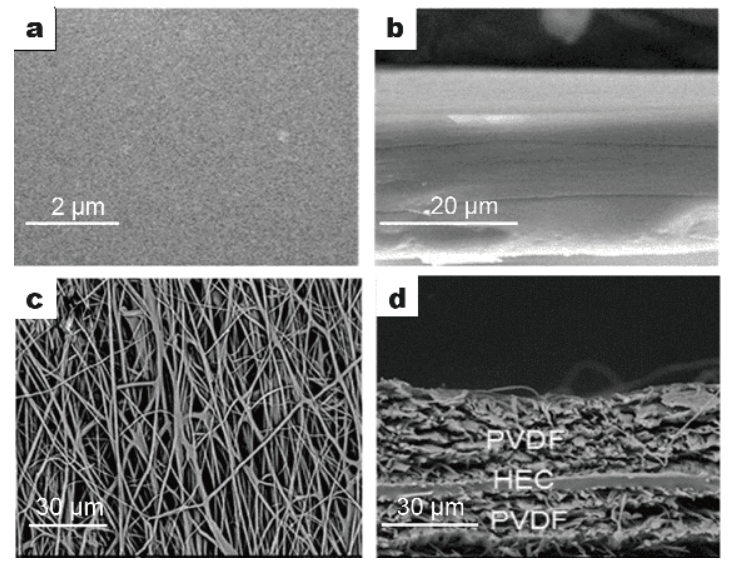

Figure 5 Scanning electron microscopy (SEM) micrographs of the surface (a: HEC; c: PVDF/HEC/PVDF) and (b: HEC; d: PVDF/HEC/ PVDF) the cross-section of membranes. Reproduced with permission from Ref. [56]. Copyright 2018, Elsevier.

that all sorts of external measures have been taken to monitor these cases, and a lot of physical designs have been adopted to protect devices, people are still uneasy to know about potential dangers inside batteries [8]. Thus, in-situ monitoring and self-adjusting smart devices can effectively address this concern $[4,62]$.

GPEs are usually prepared with organic solvents, while hydrogel polymer electrolytes are obtained by replacing such organic solvents with water. The hydrogel, featuring a polymer network structure, can capture water in the polymer matrix. The three-dimensional network formed by physical entanglement, electrostatic attraction and hydrogen bonding is generally thermally reversible. Because of this property, hydrogels have been widely used in many fields, and they are also ideal materials for responsive GEs [63]. Poly( $N$-isopropylacrylamide) (PNIPAM) has very good temperature-sensitive properties due to its hydrophilic amide group and hydrophobic isopropyl group on its macromolecular side chain. Therefore, PNIPAM and its copolymers have been widely used as a new type of smart electrolyte materials [64-68]. Jiang et al. [69] developed an electrolyte with reversible sol-gel transitions in response to heat changes. When the temperature exceeded the transition point, the solution changed into a gel state in which the ion migration was greatly inhibited. When the temperature decreased, the gel changed reversibly into solution state (Fig. 6a, b). In the bucky paper electrode test with 3-electrode configuration, when the temperature was changed from 25 to $70^{\circ} \mathrm{C}$, the tendency of the interface resistance between the electrode and electrolyte caused by different electrolytes was completely different. When the electro- 
a

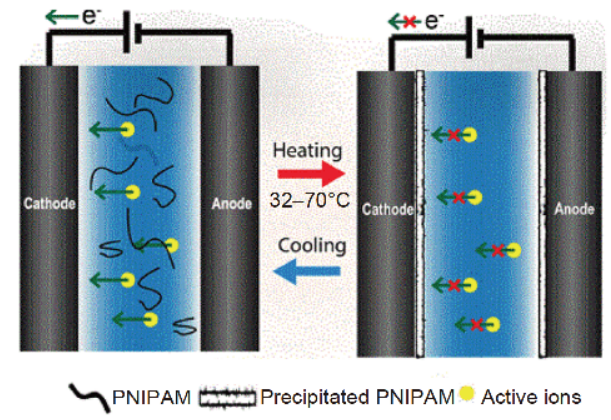

b

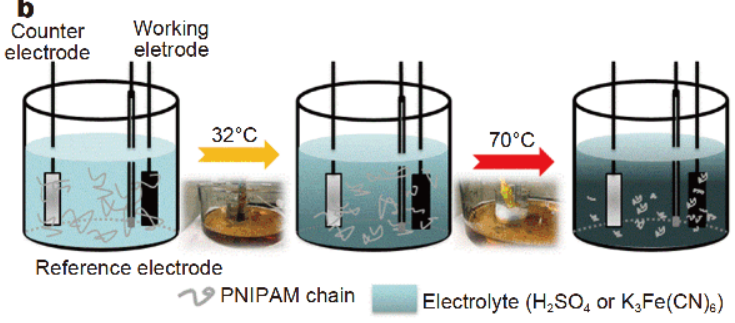

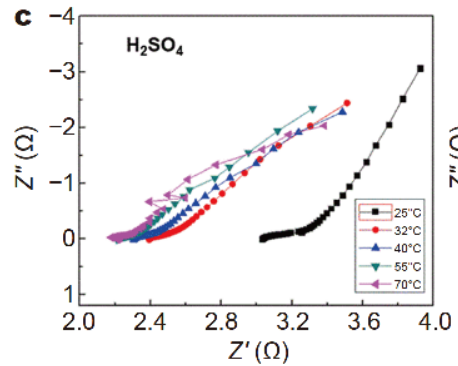
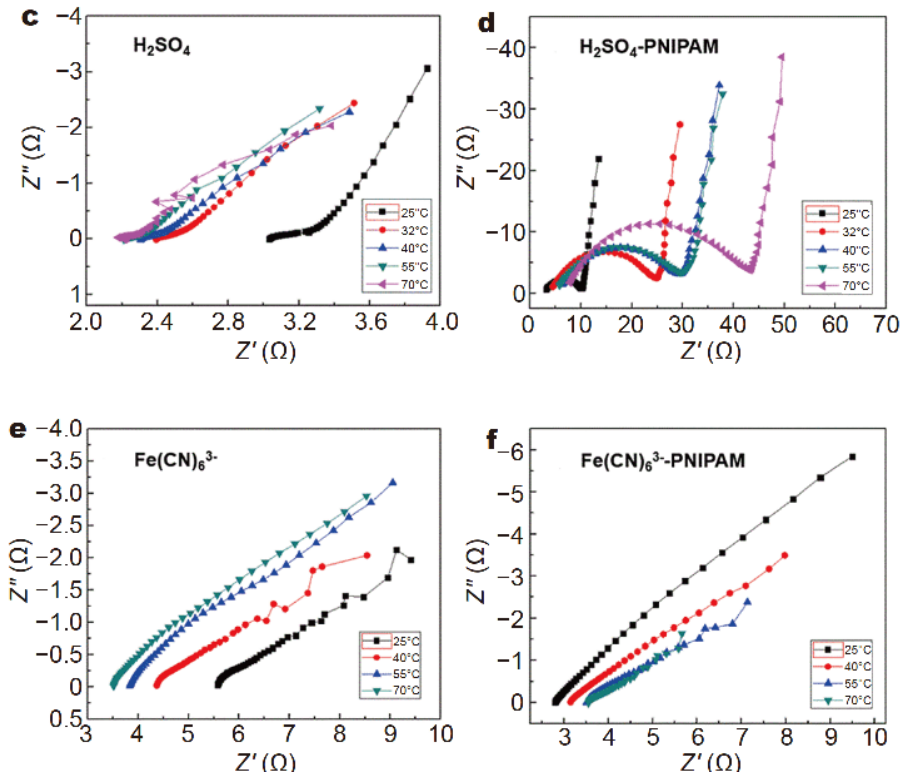

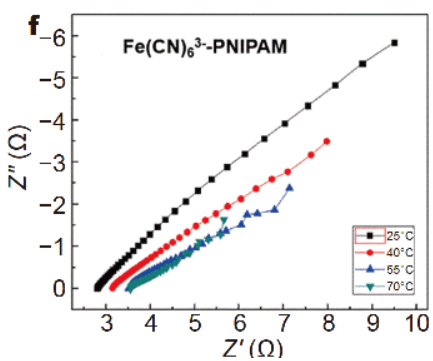

Figure 6 (a) Illustrative schematics of supercapacitors coin cell composed of a PNIPAM-based temperature-responsive electrolyte. The left panel shows the liquid state $\left(32^{\circ} \mathrm{C}\right)$ where ions are free to move and interact with electrode. The right panel shows the behavior above the LCST $\left(70^{\circ} \mathrm{C}\right)$, in which the PNIPAM chains precipitate and block active sites on the electrode surface, inhibiting ion migration. (b) Schematic of three-electrode beaker cell and optical pictures showing PNIPAM sol-gel transitions. Nyquist plots of bucky paper electrode test in the 3-electrode configuration in electrolyte solutions contain: (c) $\mathrm{H}_{2} \mathrm{SO}_{4}$, (d) $\mathrm{H}_{2} \mathrm{SO}_{4} / \mathrm{PNIPAM}$, (e) $\mathrm{Fe}(\mathrm{CN})_{6}{ }^{3-}$, (f) $\mathrm{Fe}(\mathrm{CN})_{6}{ }^{3-} / \mathrm{PNIPAM}$ at various temperatures ranging from 25 to $70^{\circ} \mathrm{C}$. Reproduced with permission from Ref. [69]. Copyright 2019, Springer.

lyte solution contained only sulfuric acid or potassium ferricyanide(III), both the charge transfer resistance $\left(R_{\mathrm{ct}}\right)$ and solution diffusion resistance $\left(R_{\mathrm{s}}\right)$ were lowered, indicating an easier ion migration (Fig. 6c, e). Conversely, when the electrolyte solution was sulfuric acid/PNIPAM or ferricyanide(III)/PNIPAM, both $R_{\mathrm{ct}}$ and $R_{\mathrm{s}}$ increased significantly (Fig. 6d, f), indicating that the electrolyte containing PNIPAM played an important role in preventing the safety hazard caused by thermal runaway and overheating operation. In addition, methyl cellulose (MC) exhibited a thermo-reversible gelation behavior in aqueous solution when temperature was elevated, and therefore it was used as stimulus-responsive electrolyte material in smart devices.

Shi et al. [70] added $\mathrm{H}_{2} \mathrm{SO}_{4}$ into $\mathrm{MC}$ to prepare electrolyte. The resulting electrolyte served in a three-electrode system to evaluate the over-temperature protection of devices (Fig. 7a, b). When the temperature was increased from 25 to $70^{\circ} \mathrm{C}$, the specific capacity declined by about $97 \%$ (Fig. $7 \mathrm{~d}$, e) and the charge/discharge time declined from 22 to $1 \mathrm{~s}$ (Fig. 7f, g). When the temperature fell below the lowest critical solution temperature (LCST), the whole system could run as before (Fig. 7c). The practicability of the same electrolyte was demonstrated by applying it in the symmetric coin-type supercapacitor.
Moreover, MC is a kind of clean energy with low cost and can respond to temperature changes at a very low concentration. Copolymerizing of PNIPAM also attracts much attention because the introduction of new monomers makes it possible to fabricate GPE with additional functions [71].

Kelly et al. [72] manufactured a copolymer of PNIPAM and acrylic acid, in which the PNIPAM served as a thermal-responsive material for the electrolyte system while the acrylic acid provided electrolyte ions (Fig. 8a). The copolymer was employed to control the electrochemical properties of polyaniline (PANI) when the temperature changed. When the temperature was raised, the copolymer experienced a phase transition activated by heat, and the local environment around the acid groups changed with the ion conductivity and concentration decrease (Fig. 8b). Moreover, the capacitance of the PANI electrode decreased by approximately $85 \%$ when the temperature changed from 22 to $50^{\circ} \mathrm{C}$ while recovered from 50 to $22^{\circ} \mathrm{C}$ (Fig. $8 \mathrm{c}, \mathrm{d}$ ), which verified the reversibility of the polymer electrolyte. Similarly, a thermal-responsive copolymer composed of PNIPAM and acrylamide was synthesized through free radical polymerization by Yang et al. [73]. This copolymer was used for the self-protection of supercapacitors because it could 

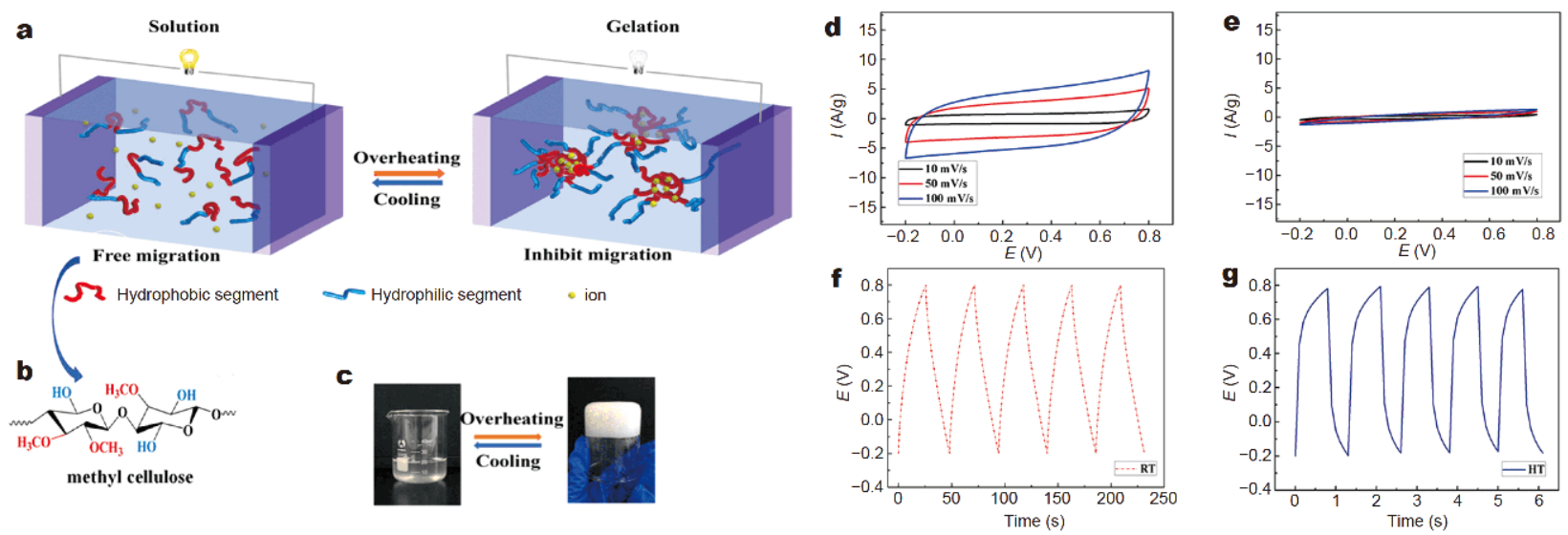

Figure 7 (a) Schematic illustration of the smart electrolyte with reversible thermo-responsive gelation properties for electrochemical energy storage devices. (b) Structures of MC, showing the hydrophilic and hydrophobic groups. (c) Digital photograph of MC solution below and above the LCST. $\mathrm{CV}$ curves performed on AC electrodes at (d) $25^{\circ} \mathrm{C}$ and (e) $70^{\circ} \mathrm{C}$. The charge/discharge characteristics in the reversible electrolyte at (f) RT, $25^{\circ} \mathrm{C}$ and (g) high temperature (HT), $70^{\circ} \mathrm{C}$. Reproduced with permission from Ref. [70]. Copyright 2018, American Chemical Society.

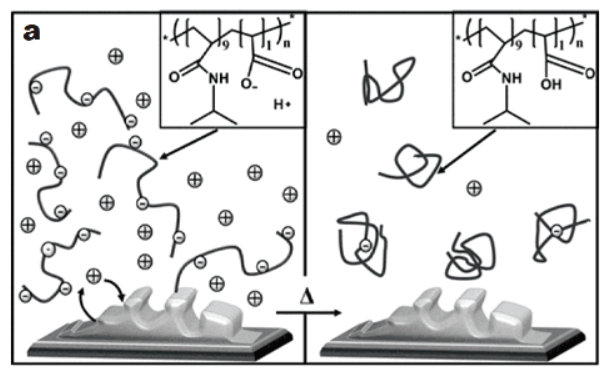

c
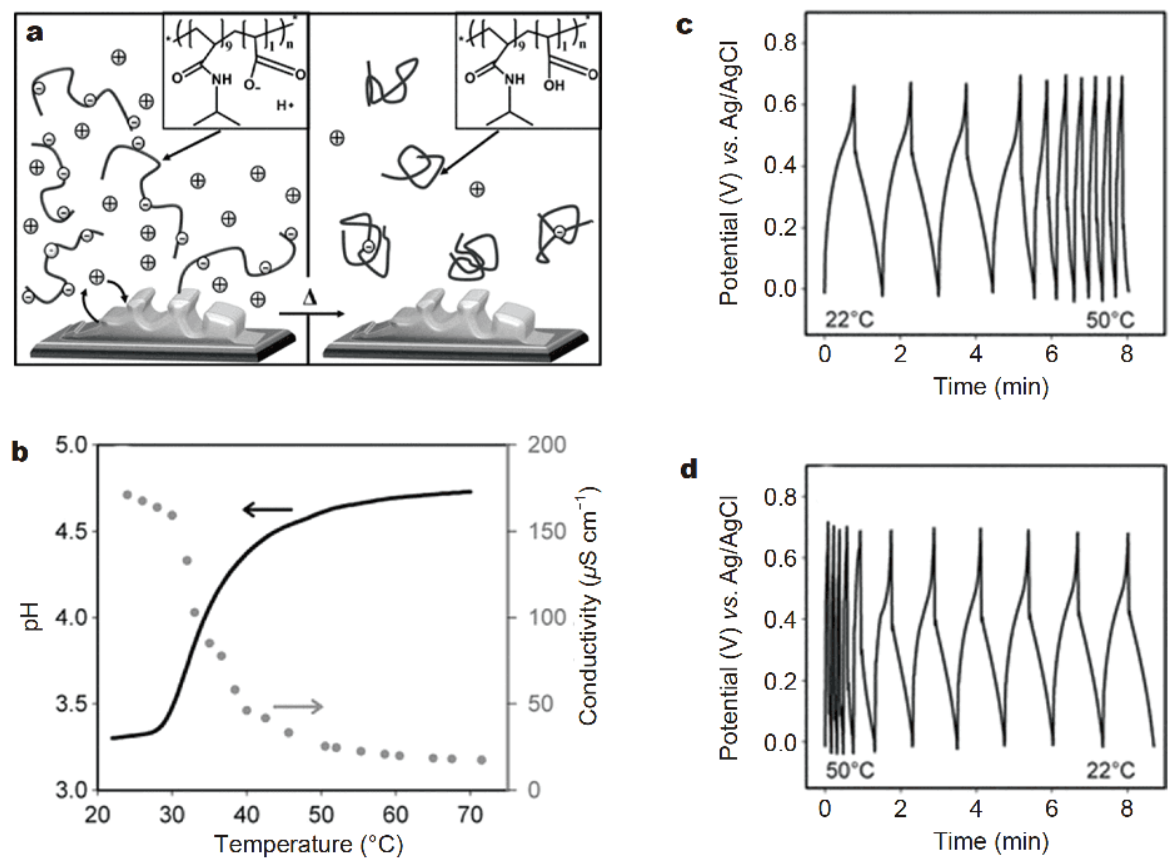

Figure 8 (a) Illustrative schematic of a thermally-controllable polymer electrolyte for electrochemical energy storage. At RT, the copolymer was dissolved and protons were dissociated (left). Above the LCST, the polymer underwent a phase transition and pulls its ions from solution (right). The inset in each panel shows the chemical structure of polymer. (b) $\mathrm{pH}$ and ionic conductivity responsive to temperature of the copolymer. Chargedischarge curve of PANI electrode in the polymer electrolyte (c) with temperature changing from 22 to $50^{\circ} \mathrm{C}$, and (d) from 50 to $22^{\circ} \mathrm{C}$. Reproduced with permission from Ref. [72]. Copyright 2012, Wiley.

undergo a thermally reversible sol-gel transition with temperature change (Fig. 9a). When the polymer absorbed a certain amount of heat, it was converted into a white hydrogel due to its hydrophobic behavior, and the migration of conductive ions was suppressed. When it was cooled, it became a solution correspondingly
(Fig. 9b), and in the meantime the electrochemical performance of the supercapacitor was renewed. More importantly, the transition temperature of the sol-gel process could be controlled by altering the molar ratio of the two monomers (Fig. 9c). Mo et al. [74] applied the same copolymer into a rechargeable $\mathrm{Zn} / \mathrm{a}-\mathrm{MnO}_{2}$ battery 

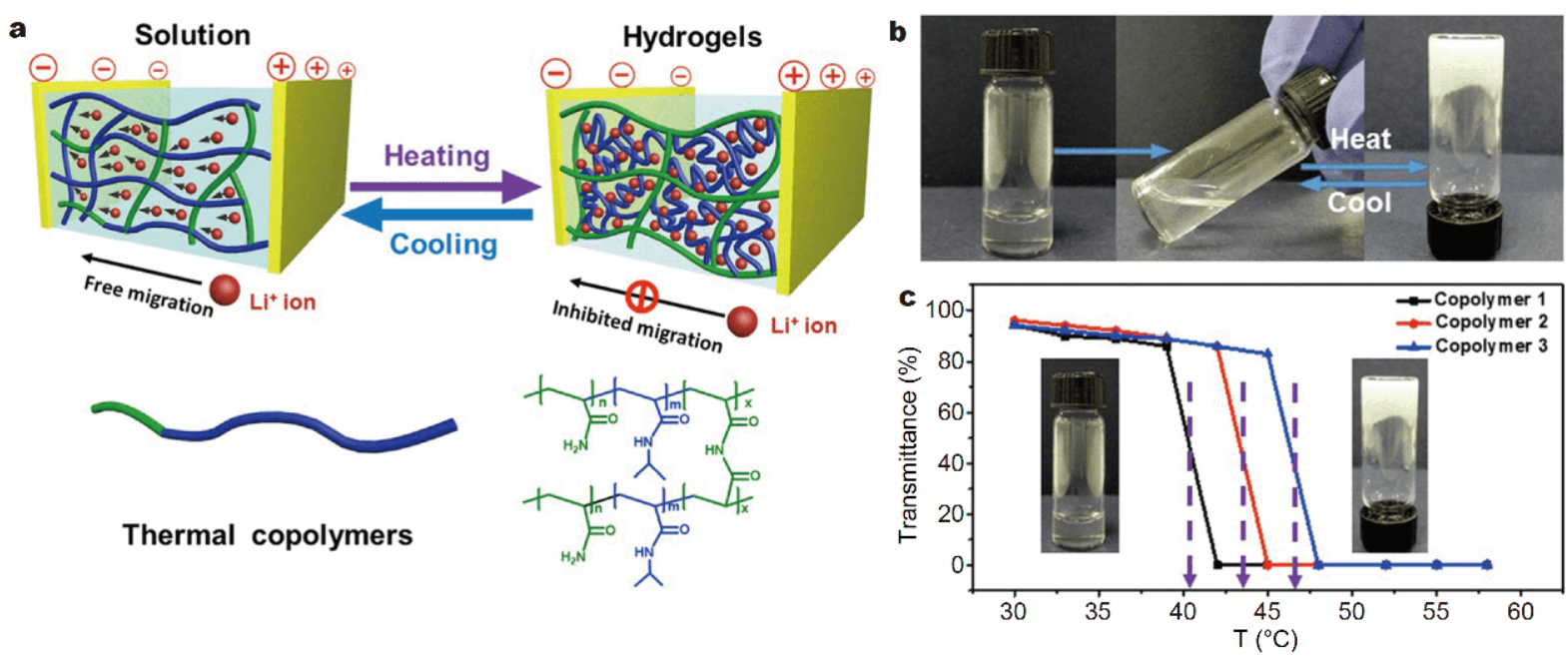

Figure 9 (a) Illustration of the sol-gel transition of electrolyte that slows the migration of conductive ions between the electrodes. Upon increasing the temperature, electrolyte solution transforms to hydrogels through the hydrophobic association. (b) Inversion experiment of reversible sol-gel transition by heating and cooling electrolyte. (c) UV-vis transmittance of copolymer solution $\left(0.2 \mathrm{~g} \mathrm{~mL}^{-1}\right)$ at $800 \mathrm{~nm}$ versus temperature. The data were obtained every $3^{\circ} \mathrm{C}$ from 33 to $58^{\circ} \mathrm{C}$. The intersection point of purple dotted line and $X$-axis showed the temperature of sol-gel transition. The molar ratios of NIPAM to AM in thermal copolymer 1, 2, and 3 were 8:1, 8:2, and 8:3, respectively. Reproduced with permission from Ref. [73]. Copyright 2012, Wiley.

system and the concept of temperature sensitive active self-protection was also confirmed.

Zhang et al. [75] presented a novel thermo-switchable micro-supercapacitor (TS-MSC) by introducing a smart electrolyte (Fig. 10a). Graft copolymerization of PNIPAM and $\mathrm{MC}$, and dissolving lithium salt in the copolymer solution afforded the electrolyte (Fig. 10b). Benefiting from the behavior of graft copolymer's reversible sol-gel transition, the TS-MSC showed a wide temperature window $\left(30-80^{\circ} \mathrm{C}\right)$ and an almost shut-off at $80^{\circ} \mathrm{C}$. Fig. 10c shows the in-situ thermal-responsive situation of the TS-MSC through the galvanostatic charge-discharge (GCD), and the areal capacitances of a temperature gradient were calculated (Fig. 10d) according to GCD curves. The results showed that the transition of sol-gel imposed an effect on the capacitance performance of the TS-MSC (Fig. 10e). Because of the microscale size, multiple TSMSCs in series or in parallel were a good way to provide the required voltage or capacitance (Fig. 10f). Among them, the series could achieve higher operating voltage, and the parallel could achieve higher capacitance (Fig. $10 \mathrm{~g}, \mathrm{~h}$ ). In addition, the feasibility of the thermal self-protection of on-chips integrated TS-MSCs could be testified by connecting the TS-MSCs with a computer $\mathrm{CPU}$ in different working conditions.

\section{Ionogel}

ILs, a sort of salts that exist as liquid at RT, have been developed over 100 years. However, scientists have only realized their unique properties in the last twenty years [76]. Fig. 11 summarized the structures and nomenclature of some commonly used ILs [77]. As the electrolyte for many kinds of electrochemical storage devices, its high ionic conductivity, high electrochemical stability, nonflammability, negligible volatility, wide electrochemical window as well as the high thermal stability make it the first choice in many applications. However, its low cycling properties and leakage limit the development in lots of fields, and this problem should not be ignored [78-81]. As mentioned above, GPEs have become potential materials for replacing LEs in many energy devices. Ionogel polymer electrolytes provide a novel way to make full use of ILs. They combine the advantages of good mechanical properties of polymer gel with a variety of applications of ILs [82]. Therefore, they can be used as safer electrolytes of devices.

Taghavikish et al. [83] prepared chemically crosslinked polyionic liquid (PIL) GE using 2-hydroxyethyl methacrylate (HEMA) monomer and a polymerizable IL, 1,4-di (vinylimidazolium) butanebisbromide (DVIMBr) in an IL 1-butyl-3-methylimidazolium hexafluorophosphate $\left(\mathrm{BMIMPF}_{6}\right)$, which acted as the polymerization solvent (Fig. 12). The in-situ entrapment of the IL(BMIMPF $\left.{ }_{6}\right)$ in the gel during the polymerization and crosslinking of polymer was realized. The polymerization and crosslinking were caused by the $\operatorname{IL}\left(\mathrm{BMIMPF}_{6}\right)$, which was 
a

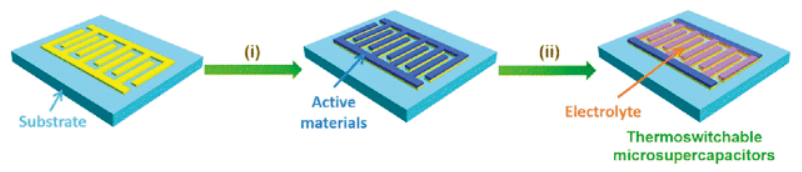

b
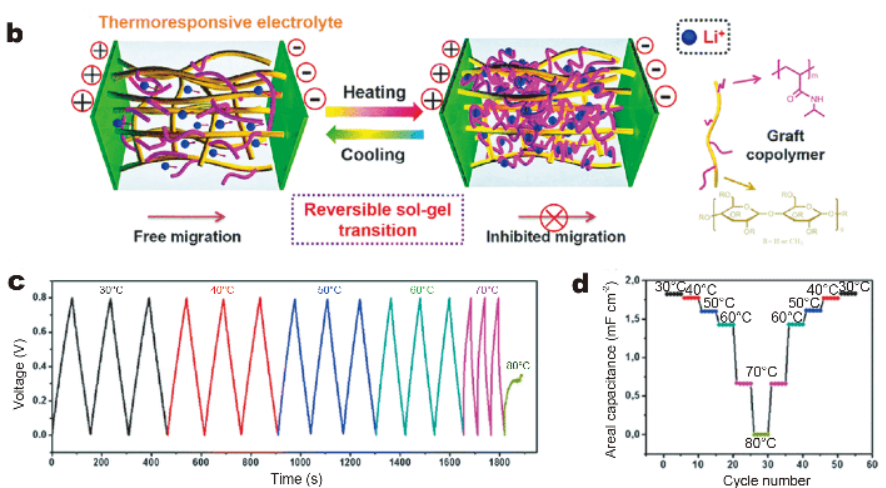

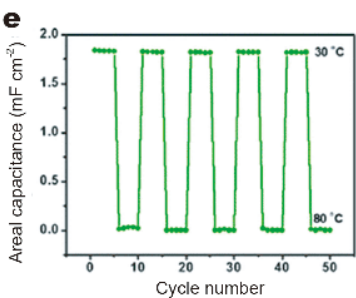

f
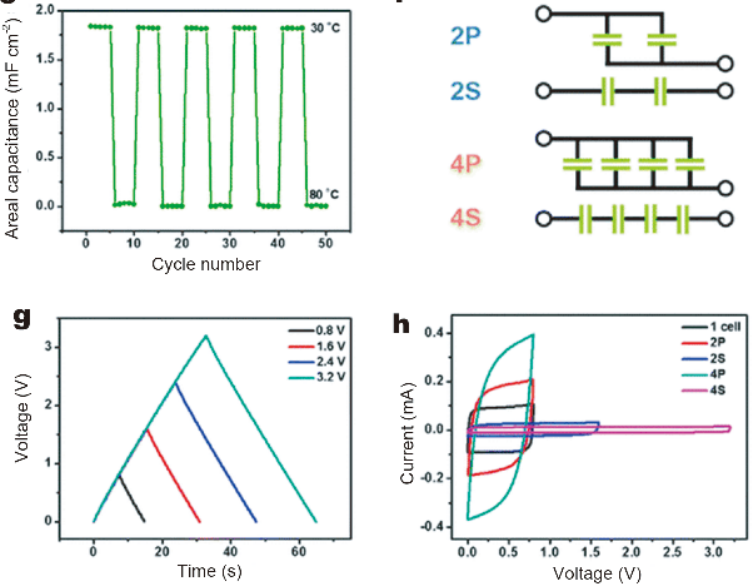

Figure 10 Design and fabrication of a TS-MSC. (a) Schematic illustration of the fabrication of a TS-MSC on both a Si wafer and a polyimide (PI) film. The fabrication process included patterning interdigital gold current collectors through photolithography, preparation of active material (PEDOT) layers through an electrodeposition method (i), and drop-casting of a LiCl-dissolved PNIPAAm/MC solution as thermo-responsive electrolyte (ii). (b) Illustration of the reversible sol-gel transition for the thermo-responsive electrolyte and ion transport between interdigital electrodes under heating and cooling. (c) GCD curves at different temperatures from 30 to $80^{\circ} \mathrm{C}$. (d) Areal capacitance as a function of temperature from 30 to $80^{\circ} \mathrm{C}$ at a current density of $20 \mu \mathrm{A} \mathrm{cm}^{-2}$. (e) Reversible areal capacitance behavior of TS-MSCs with sol-gel transition for 50 heating-cooling cycles. (f) Circuit diagrams of two and four TS-MSCs connected in series and parallel. (g) GCD curves of TS-MSCs with four units connected in series at a current density of 60 $\mu \mathrm{A} \mathrm{cm}^{-2}$. (h) $\mathrm{CV}$ curves at a scan rate of $200 \mathrm{mV} \mathrm{s}^{-1}$. Reproduced with permission from Ref. [75]. Copyright 2018, Royal Society of Chemistry.

directly entrapped upon the formation of the crosslinked network. The TGA measurements showed that the PIL had excellent mechanical properties and thermal stabilities. It was a strong interaction between the imidazolium groups of DVIMBr and the hydroxyl groups of HEMA that significantly increased their thermal stability.

Hazama et al. [84] prepared IL gel through tetra-poly (ethylene glycol) (PEG) network with the polymer content of about 5-6 wt\%, which was the lowest among the GEs for LIBs. In the LIB system, the tetra-PEG network contained $1.0 \mathrm{~mol} \mathrm{~L}^{-1} \mathrm{LiPF}_{6}$ in a binary or ternary system, i.e., EC/DEC and EC/DEC/TFEP (EC: ethylene carbonate, DEC: diethyl carbonate, and TFEP: tris(2,2,2-trifluoroeth-yl) phosphate (Fig. 13a). The tetra-PEG gel based on ternary EC + DEC + TFEP system was found nonflammable when the TFEP content in ternary mixture was higher than $20 \mathrm{wt} \%$ through a direct flame test (Fig. 13b, c). In addition, the one that contained TFEP could be used as GEs with high safety. The gelation mechanism of tetra-PEG in ILs was put forward by Hashimoto et al. [85]. Ishikawa et al. [86] prepared IL gel with an ultralow polymer content based on $1 \mathrm{wt} \%$ of tetra-PEG and $99 \%$ of IL (Fig. 14). The liquid in this experiment was 1-ethyl-3-methylimidazolium bis(fluorosulfonyl) amide, $\left.\left[\mathrm{C}_{2} \mathrm{mIm}\right][\mathrm{FSA}]\right)$. This kind of IL GEs were proved to exhibit ideal ionic conductivity, and more importantly, they were very promising for the electrochemical devices which were highly safe. Zhou et al. [87] designed and synthesized star-shaped PILs with threearmed and four-armed structures. Compared with the single-armed ones, these PILs could decrease the glass transition temperature $\left(T_{\mathrm{g}}\right)$ and crystallinity. Consequently, the electrochemical properties were obviously improved. The TGA results showed that PIL-GPE-4, PIL-GPE-3 and PIL-GPE-1 were thermally stable up to $310^{\circ} \mathrm{C}$. Additionally, the decomposition temperatures were higher when the PILs were more branched. Raut et al. [88] fabricated ionogel membranes by using macro-porous syndiotactic polystyrene (sPS) in which a specific IL, 1butyl-1-methylpyrrolidinium bis(trifluoromethylsulfonyl) imide (PYR14TF2N), was incorporated into the porous. At the same time, similar ionogel membranes were manufactured by filling the pores of polyolefin (such as polyethylene and polypropylene) with the same IL. By contrast, the sPS owned a high crystalline melting temperature $\left(270^{\circ} \mathrm{C}\right)$ and $T_{\mathrm{g}}\left(T_{\mathrm{g}} \approx 105^{\circ} \mathrm{C}\right)$. Similarly, because the thermal stability of the electrolytes was the pivotal performance for the safety and stability of devices, TGA and DSC data could perfectly demonstrate that sPS gel membranes were more suitable for high-temperature 


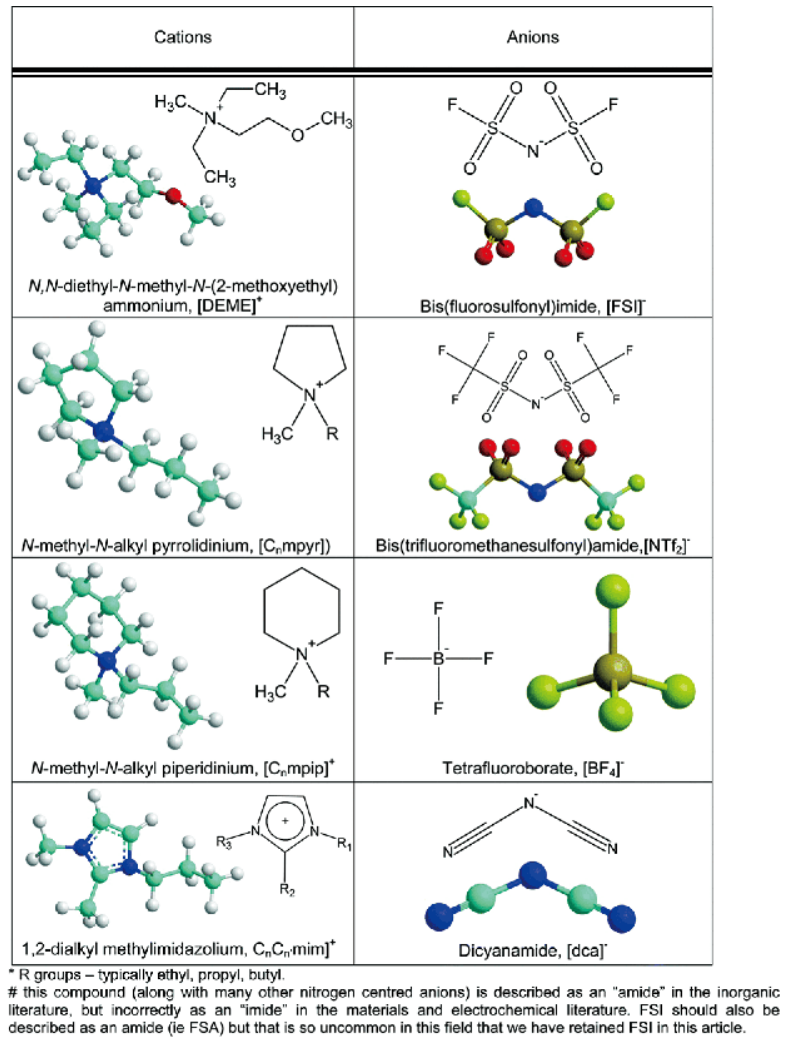

Figure 11 Common IL ion families appearing in energy applications and their commonly used acronym systems. In acronyms such as $\left[\mathrm{C}_{n} \mathrm{mpyr}\right]^{+}$, the subscript " $n$ " indicates the number of carbons in the alkyl substituent. Reproduced with permission from Ref. [77]. Copyright 2014, Royal Society of Chemistry.
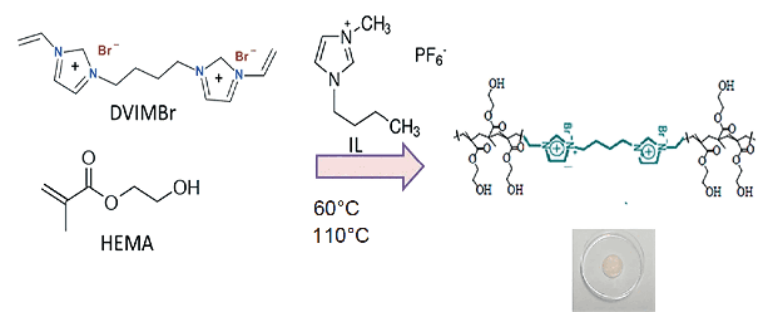

Figure 12 Schematics of polymerization of PIL GE. Reproduced with permission from Ref. [83]. Copyright 2018, Nature Publishing Group.

applications.

\section{LOW MOLECULE-MASS ORGANIC GELATOR-BASED GEL ELECTROLYTE}

Besides stimulus-responsive GPEs, low molecule-mass organic gelator (LMOG)-based GEs have gradually gained more and more attention because they also have sensitive properties to the external environment changes [89,90]. LMOG-based GEs, the main components of
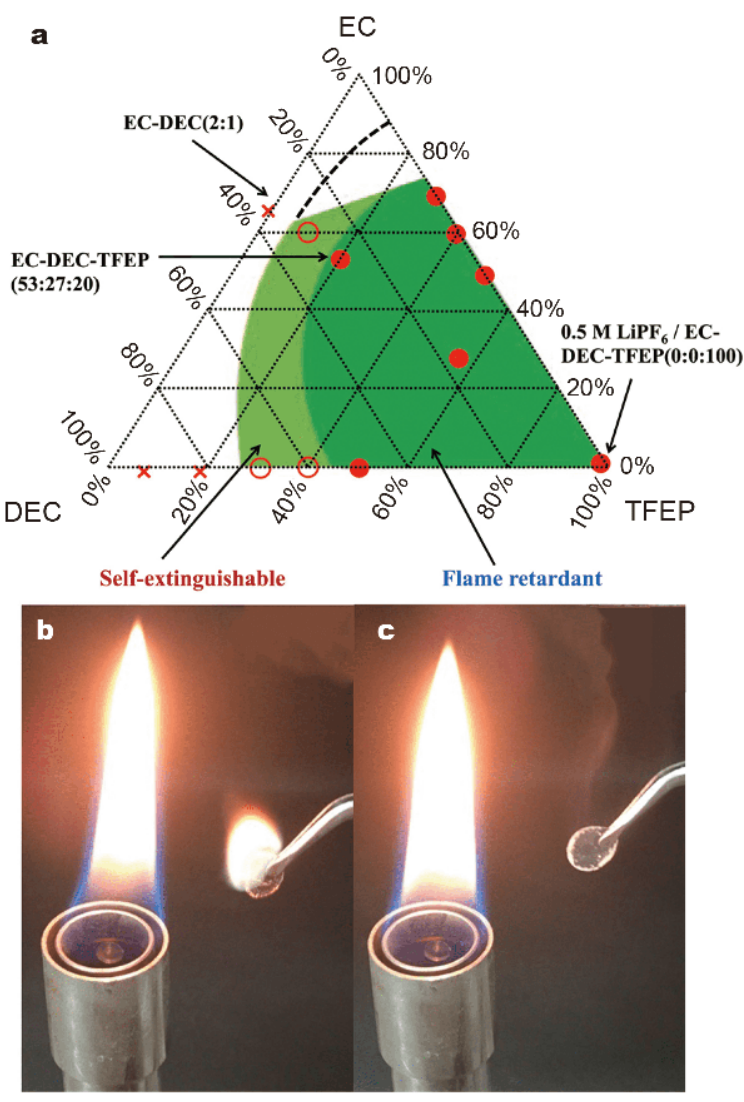

Figure 13 (a) Composition diagram for $1.0 \mathrm{~mol} \mathrm{~L}^{-1} \mathrm{LiPF}_{6}$ in ternary EC + DEC + TFEP solutions at RT. Photographs showed the results of combustion test for tetra-PEG GEs with (b) $1.0 \mathrm{~mol} \mathrm{~L}^{-1} \mathrm{LiPF}_{6} / \mathrm{EC}+\mathrm{DEC}$ (2:1) and (c) $1.0 \mathrm{~mol} \mathrm{~L}^{-1} \mathrm{LiPF}_{6} / \mathrm{EC}+\mathrm{DEC}+\operatorname{TFEP}(53: 27: 20)$. Reproduced with permission from Ref. [84]. Copyright 2015, Elsevier.

which are usually conductive ions, organic solvent or water, and the gelator can be categorized into mono- or poly-organic low molecule-mass molecules.

Most LMOGs are mainly used in dye-sensitized solar cells (DSSCs). However, the traditional electrolytes are easy to leak because most of the electrolytes are liquid. Therefore, their safety and long-term stability are limited [91,92]. Replacing the LEs with solid-state hole transport conductors and ILs has been proposed to overcome this issue, but yet resulted in other problems. Thus, the GEs formed by the LMOG, featuring the merits of both LEs and SEs, have been given extensive attention. These LMOGs are mainly classified into amino acid compounds, saccharide derivatives, amide compounds and biphenyl compounds. LMOGs have a unique feature of favorable solubility once heated and the ability to induce smooth gelation of low solubility organic liquids. Yu et al. [93] scrutinized the impact of the additive LMOG cyclohexanecarboxylic acid-[4-(3-octadecylureido) phenyl] 


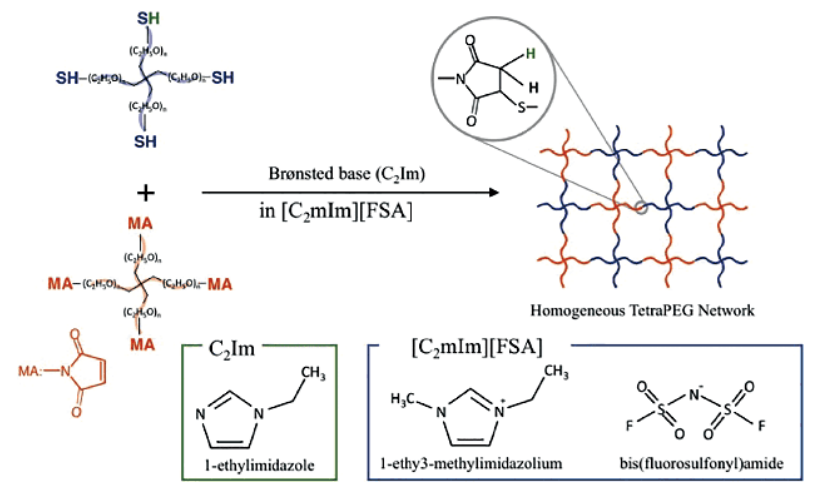

Figure 14 Schematic illustration of the gelation reaction of tetra-PEGs with maleimide (MA) and thiol (SH) terminals, and chemical structures of $\mathrm{C}_{2} \mathrm{Im}$ and IL examined in this work. Reproduced with permission from Ref. [86]. Copyright 2019, Elsevier.

amide to solidify the 3-methoxypropionitrile based LEs, and the as-formed DSSC exhibited an efficiency as high as 9.1\% when irradiated at simulated AM1.5G full sunlight with an excellent stability under thermal and light-soaking dual stress.

Tao et al. [94] prepared a series of diamide derivatives as LMOGs. $N, N^{\prime}$-methylene-bis-dodecanamide was used as LMOG to solidify the IL 1-methyl-3-hexyl-imidazolium iodide based ILEs (Fig. 15a). The new ion gel electrolyte (IGE) featured a high gel-sol transition temperature $\left(T_{\text {gel }}\right)$ of $127^{\circ} \mathrm{C}$ (Fig. $15 \mathrm{c}$ ), contributing to the thermal safety properties of devices. Although the photoelectric conversion efficiency of IGE-based DSSC was lower than that of ILE-based DSSC, the former showed a much better stability. As shown in Fig. 15b, the DSSC with IGE exhibited excellent durability with almost no degradation in both thermal and light soaking accelerated aging tests. The $N, N^{\prime}-1,4$-butylenediylbis-dodecanamide was applied to gelate the 1,2-dimethyl-3-propyl-imidazolium iodide (DMPII), and the resulting IGE had a $T_{\text {gel }}$ of $115.8^{\circ} \mathrm{C}$. [95]. $N, N^{\prime}-1,5$-pentanediylbis-dodecanamide was employed to gelate the DMPII, resulting in an IGE with a $T_{\text {gel }}$ of $108^{\circ} \mathrm{C}$ [96], and to gelate acetonitrile-based LEs, resulting in an IGE with a $T_{\text {gel }}$ of $80.5^{\circ} \mathrm{C}$ [97] (Fig. 16). In addition, Tao's group [98] made a comparison of LMOGs containing different numbers $(2,6,5$ and 9) of methylene groups $\left(-\mathrm{CH}_{2}-\right)$ between the two amide carbonyl groups (Fig. 17a), and these LMOGs exhibited distinctive self-assembly behaviors. They found that the parity of the number of $-\mathrm{CH}_{2}-$ had a great impact on the self-assembly behavior of gelators which came into being different morphologies. The DSC of this series of LMOG in MePN-based electrolytes showed the $T_{\text {gel }}$ of all was
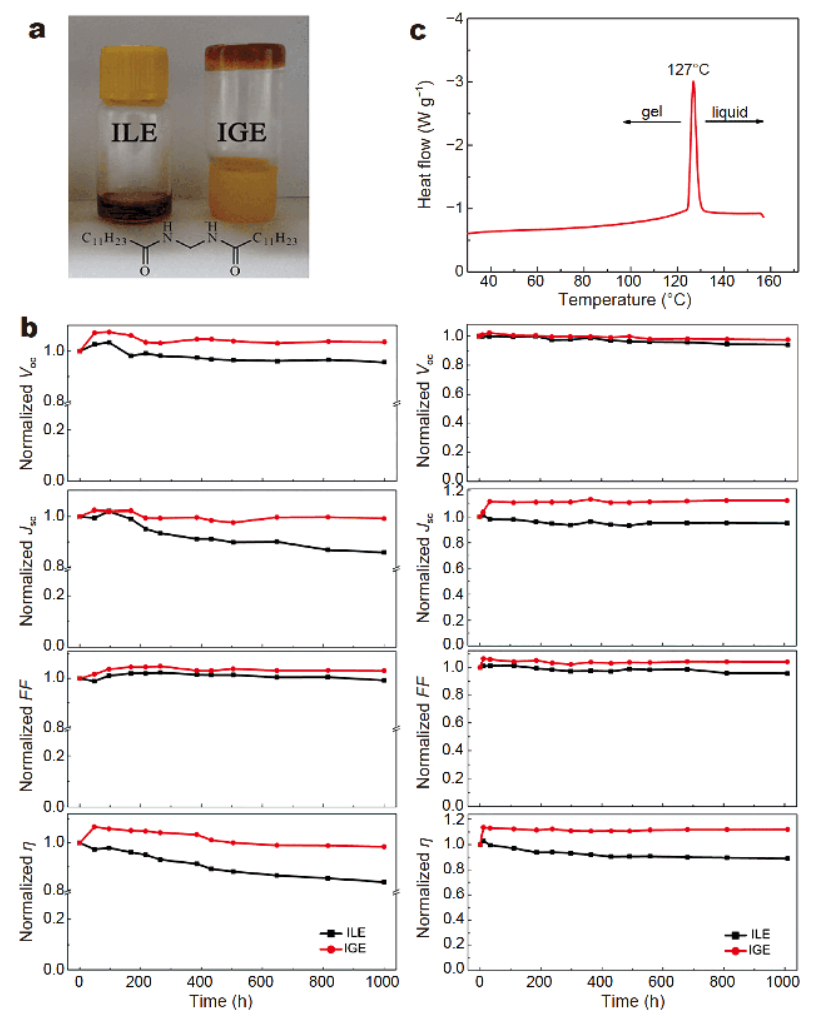

Figure 15 (a) Photo of ILE and IGE with LMOGs. (b) Normalized device efficiency variations with the DSSCs based on ILE and IGE (left) at $60^{\circ} \mathrm{C}$ and (right) under successive sun light soaking with UV cutoff filter at $50^{\circ} \mathrm{C}$ for $1000 \mathrm{~h}$. (c) DSC thermogram of IGE. Reproduced with permission from Ref. [94]. Copyright 2015, Elsevier.

over $100^{\circ} \mathrm{C}$, which indicated the excellent thermal stability (Fig. 17b). The LMOGs containing odd-numbered $-\mathrm{CH}_{2}-$ groups owned higher $T_{\text {gel }}$ compared with those with even-numbered $-\mathrm{CH}_{2}-$ groups, meaning that the former could construct a more stable network than the latter. The same group also tried to design and study many kinds of bi-component LMOG as co-gelators and applied them in DSSCs, including $N, N^{\prime}-1,5$-pentanediylbis-dodecanamide and 4-(Boc-aminomethyl) pyridine (herein, Boc is abbreviated for $t$-butyloxy carbonyl) [99], $N, N^{\prime}$-1,8-octanediylbis-dodecanamide and iodoacetamide [100], bisamide and valine [101], 1,6-diaminohexane and $N, N^{\prime}$-1,3-propanediylbis-dodecanamide, as well as adipic acid and $N, N^{\prime}-1,3$-propanediylbis-dodecanamide [102]. All of these LMOGs as co-gelators had positive change on the photovoltaic performance of DSSCs and their thermal stability. Another effective strategy to gelate LEs was to introduce nanoparticle to the LMOG-based GEs [103]. Girma et al. [104] combined $\mathrm{TiO}_{2}$ nanoparticles with a LMOG $N, N^{\prime}$-1,3-propanediylbis-dodecanamide as well as 

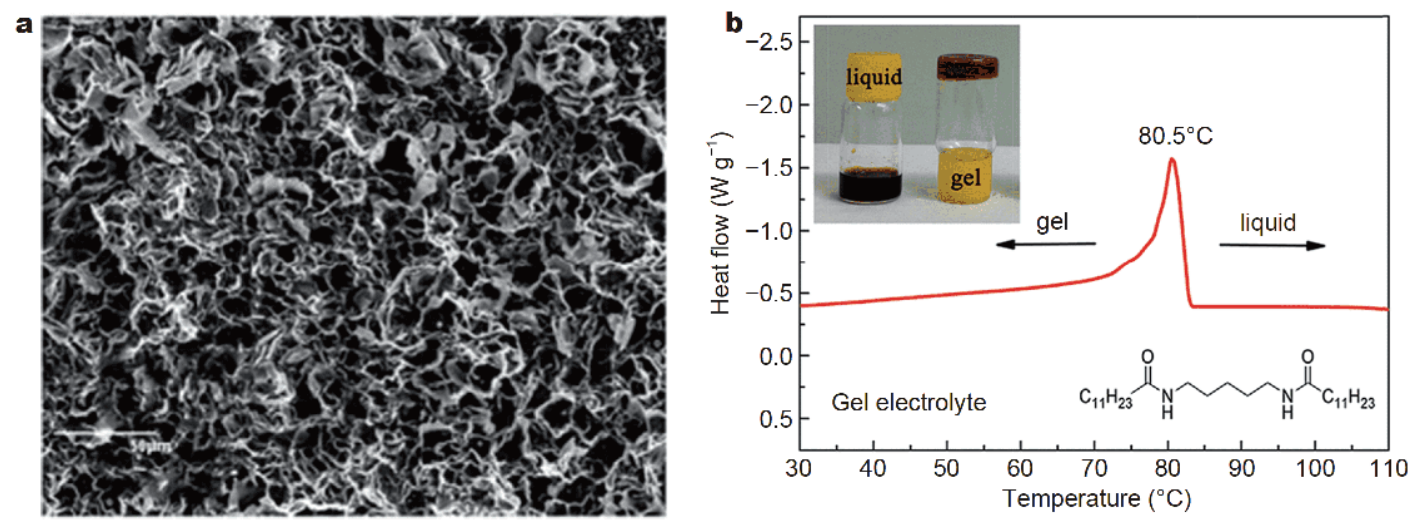

Figure 16 (a) SEM image of the xerogel based on $N, N^{\prime}-1,5$-pentanediylbis-dodecanamide. (b) DSC thermogram of the GE. Reproduced with permission from Ref. [97]. Copyright 2015, Royal Society of Chemistry.
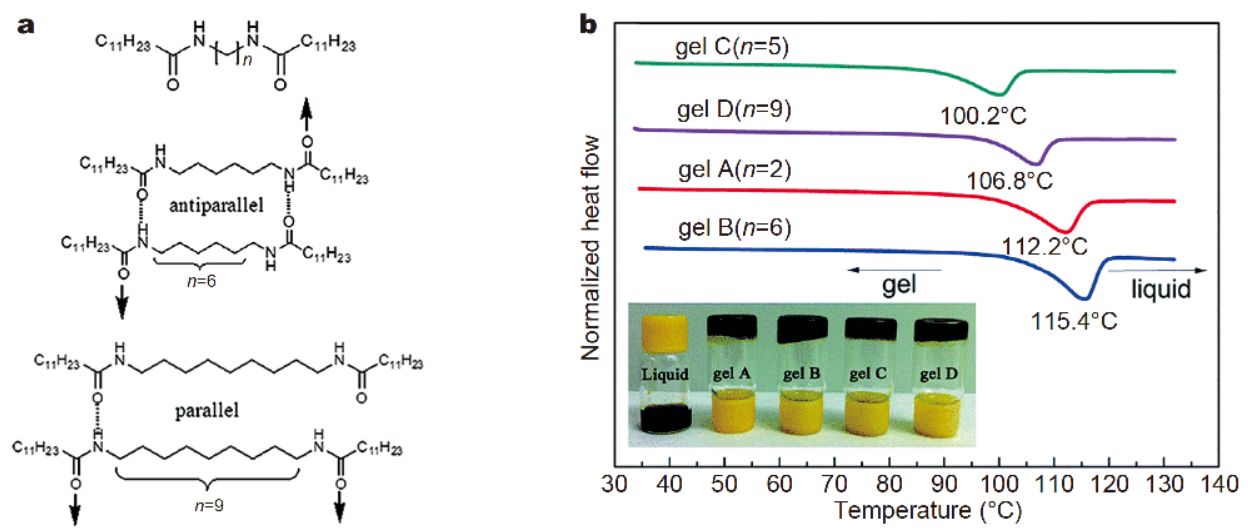

Figure 17 (a) Chemical structures of didodecanoylamides of $\alpha, \omega$-alkylidenediamines $(n=2,5,6$, and 9) (above) and self-assembly structures of gelator B $(n=6)$ (middle) and gelator D $(n=9)$ (below). (b) DSC thermograms of the GEs. Reproduced with permission from Ref. [98]. Copyright 2014, American Chemical Society.

an ion liquid DMPII to obtain a nanoparticle-gel composite electrolyte (NPgel) (Fig. 18a). Meanwhile, the electrolytes, liquids and gel NPgel were assembled in the DSSCs and tested for their performance. The NPgel demonstrated superior performance over another two in both photovoltaic conversion efficiency (PCE) and stability (Fig. 18b).

\section{FUMED SILICA- AND SILOXANE-BASED GEs}

LABs have a history of over 150 years since their invention in 1859. Because of the rich raw materials and the ease to produce and recycle, LABs have been in the leading position for a long time and are still in widespreading application $[105,106]$. However, traditional LABs have major drawbacks. For example, it is necessary to add water to maintain the system in use, because water will be decomposed into hydrogen and oxygen at the end of charging. Additionally, the overflowing gas will corrode the surrounding equipment and pollute the environment due to the presence of acid mist. Valveregulated lead-acid batteries (VRLAs) were designed to minimize the replenishment of water and to avoid liquid spillage [106]. In VRLAs, the electrolyte is the key factor that affects the performance of batteries. Gelation is one of the two technologies to immobilize the electrolyte, while the other one is absorptive glass mat (AGM). Generally, AGM-VRLAs are sensitive to the working temperature. When the temperature is increased, it will accelerate the production of oxygen, the drying-out of internal resistance, the unstable thermal runaway and the explosion of batteries in extreme cases. The mainly used gelators contain colloid silica-, fumed silica-, and polysiloxane-based gels [107-109]. Usually, the colloid silica has a three-dimensional structure which features low capacity, low stability and poor thixotropy. The employ- 

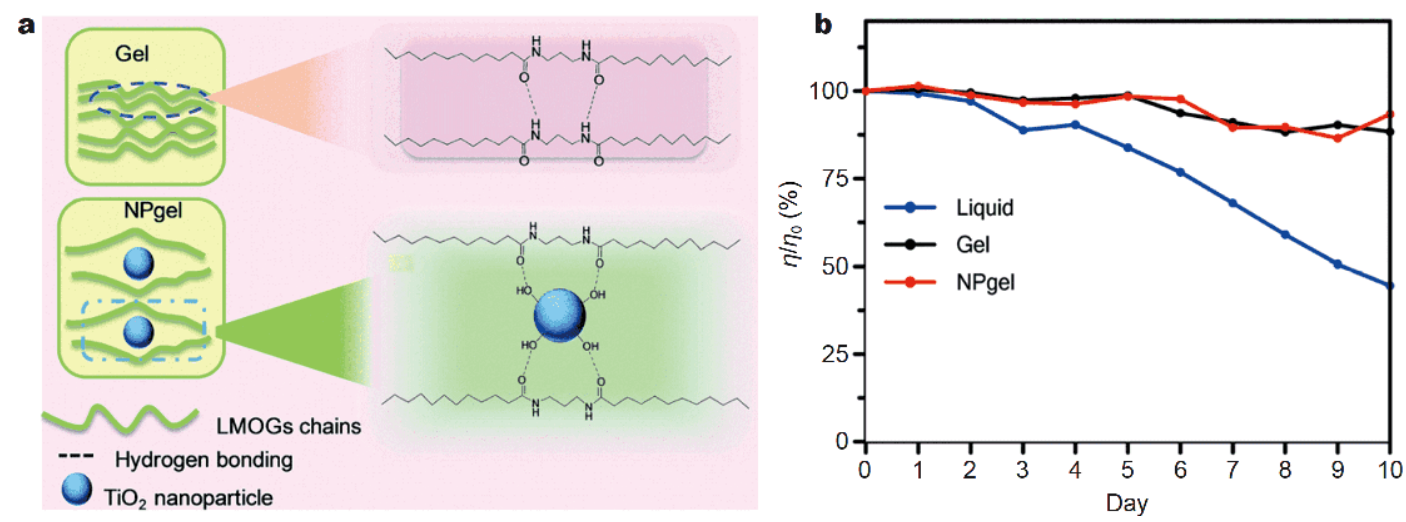

Figure 18 (a) Schematic representations of the interaction of LMOG chains in the GE (above) and the interaction between the $\mathrm{LMOG}$ chain and $\mathrm{TiO}_{2}$ nanoparticles in the NP GE (below). (b) Variation in the normalized efficiency of the DSSCs based on the liquid, gel, and NP GEs measured for 10 days. Reproduced with permission from Ref. [104]. Copyright 2017, the Royal Society of Chemistry.

ment of fumed silica improved this a lot. Chen et al. [110] carried out fundamental studies on how the preparation condition and the particle size distribution of fumed silica affected VRLAs. They found that the optimal mechanical mixing time and the operational temperature were the key factors in preparing GEs with high capacity and low internal resistance. Pan et al. [111] mixed colloidal silica and fumed silica in a certain ratio to prepare hybrid gel. This hybrid gel showed a longer time for gelation and a better cross-linking structure in physical nature. Both of its electrochemical performance and safety were improved compared with those of the individuals. In addition, the additive also contributed a lot in the way of improving batteries. Tantichanakul et al. [112] combined AGMs with gel technology to compare with traditional non-gel AGMs. Verataldehyde had been tested as an additive. At $100 \%$ depth of discharge, the gel-type AGM enhanced the battery performance, and the introduction of veratraldehyde inhibited the hydrogen evolution of sulfuric acid to a certain extent, and thus improved the safety performance of the whole system. Tantichanakul et al. [113] analyzed the different influence of the concentration of $\mathrm{SiO}_{2}$ and the four kinds of organic additives: PMMA, polypyrole (PPy), polyacrylamide (PAM) and vaniline (VA). They found that both the increase of the concentration of $\mathrm{SiO}_{2}$ and the addition of PAM or VA could shorten gelling time and strengthen gels. However, the introduction of PMMA or PPy did not show a significant influence on gelling process. Gençten et al. [114] used inorganic additives gibbsite and boehmite to lower corrosion. However, the high cost of fumed silica and the difficult processing method cannot allow them a wider range of application. Polysiloxane, which has been ap- plied in the electrochemical system, is in an increasing tendency because of its thermal, chemical and mechanical stability. Tang et al. [115] prepared polysiloxane-based $\mathrm{GE}$ (PBGE) and studied the difference between the PBGE-AGM and AGM-colloid silica GE (CSGE) hybrid batteries. The PBGE showed an effective improvement of the low- and high-temperature properties.

\section{CONCLUSION AND FUTURE PERSPECTIVES}

In conclusion, with the increasing demand for electrochemical devices with high safety performance, the field of electrolytes in equipment power supplies has been the focus and hotspot of research. In this context, the safety regulation of electrochemical energy storage devices has become a key issue, and the development of GEs has contributed greatly to this respect.

When traditional GPE is still evolving, the current work is mainly to study different polymerization methods of polymer backbone and the compounding with additives or modifying the polymer backbone by grafting or doping to improve the thermal stability of GEs and to ensure its safety performance. The LE to be gelled is replaced with an IL to form anionic GE, which further increases the thermal decomposition temperature. Organic low molecule-mass GEs are mostly used in DSSCs. In addition, a class of polymer-based thermally-responsive GEs have evolved, which fairly accords with the smart age. However, most responsive materials are limited to the modification based on PNIPAM and PEO, and the devices that can use these responsive materials are very limited. As a result, it is highly desirable to develop new responsive polymer gels and imperative to enhance the 
compatibility of GEs with a variety of devices and maintain overall electrochemical and cycle stability. Moreover, the unique flexibility of GEs can theoretically give a wider range of application to energy storage devices, and responsive GEs can provide convenience for today's work and life. Therefore, the study of such electrolytes is of great significance for improving the safety of energy storage equipment and improving people's work and living conditions. Furthermore, these thermally responsive electrolytes only verify their feasibility, and there is still much work to be done before their actual promotions and applications.

Received 16 May 2019; accepted 22 July 2019; published online 28 August 2019

1 Mahlia TMI, Saktisahdan TJ, Jannifar A, et al. A review of available methods and development on energy storage; technology update. Renew Sustain Energy Rev, 2014, 33: 532-545

2 Yoo HD, Markevich E, Salitra G, et al. On the challenge of developing advanced technologies for electrochemical energy storage and conversion. Mater Today, 2014, 17: 110-121

3 Díaz-González F, Sumper A, Gomis-Bellmunt O, et al. A review of energy storage technologies for wind power applications. Renew Sustain Energy Rev, 2012, 16: 2154-2171

4 Cheng X, Pan J, Zhao Y, et al. Gel polymer electrolytes for electrochemical energy storage. Adv Energy Mater, 2018, 8: 1702184

5 Peng L, Fang Z, Zhu Y, et al. Holey 2D nanomaterials for electrochemical energy storage. Adv Energy Mater, 2018, 8: 1702179

6 Shi Y, Peng L, Ding Y, et al. Nanostructured conductive polymers for advanced energy storage. Chem Soc Rev, 2015, 44: 6684-6696

7 Mai L, Tian X, Xu X, et al. Nanowire electrodes for electrochemical energy storage devices. Chem Rev, 2014, 114: 1182811862

8 Jiang J, Li Y, Liu J, et al. Recent advances in metal oxide-based electrode architecture design for electrochemical energy storage. Adv Mater, 2012, 24: 5166-5180

9 Tarascon JM, Armand M. Issues and challenges facing rechargeable lithium batteries. Nature, 2001, 414: 359-367

10 Palacín MR, de Guibert A. Why do batteries fail? Science, 2016, 351: 1253292

11 Wang Y, Zhong WH. Development of electrolytes towards achieving safe and high-performance energy-storage devices: A review. ChemElectroChem, 2015, 2: 22-36

12 Zhu Y, He X, Mo Y. Strategies based on nitride materials chemistry to stabilize Li metal anode. Adv Sci, 2017, 4: 1600517

13 Tatsuma T, Taguchi M, Iwaku M, et al. Inhibition effects of polyacrylonitrile gel electrolytes on lithium dendrite formation. J Electroanal Chem, 1999, 472: 142-146

14 Tatsuma T, Taguchi M, Oyama N. Inhibition effect of covalently cross-linked gel electrolytes on lithium dendrite formation. Electrochim Acta, 2001, 46: 1201-1205

15 Wu B, Liu Q, Mu D, et al. New desolvated gel electrolyte for rechargeable lithium metal sulfurized polyacrylonitrile (S-PAN) battery. J Phys Chem C, 2014, 118: 28369-28376

Zhu M, Wu J, Zhong WH, et al. A biobased composite gel polymer electrolyte with functions of lithium dendrites suppressing and manganese ions trapping. Adv Energy Mater, 2018, 8: 1702561

17 Zhang P, Zhu J, Wang M, et al. Lithium dendrite suppression and cycling efficiency of lithium anode. Electrochem Commun, 2018, 87: $27-30$

18 Hoang TKA, Doan TNL, Cho JH, et al. Sustainable gel electrolyte containing pyrazole as corrosion inhibitor and dendrite suppressor for aqueous $\mathrm{Zn} / \mathrm{LiMn}_{2} \mathrm{O}_{4}$ battery. ChemSusChem, 2017, 10: $2816-2822$

19 Wang P, Zakeeruddin SM, Moser JE, et al. A stable quasi-solidstate dye-sensitized solar cell with an amphiphilic ruthenium sensitizer and polymer gel electrolyte. Nat Mater, 2003, 2: 402407

20 Chen W, Lei T, Wu C, et al. Designing safe electrolyte systems for a high-stability lithium-sulfur battery. Adv Energy Mater, 2018, 8: 1702348

21 Liang SS, Yan WQ, Wu X, et al. Gel polymer electrolytes for lithium ion batteries: Fabrication, characterization and performance. Solid State Ionics, 2018, 318: 2-18

22 Fenton DE, Parker JM, Wright PV. Complexes of alkali metal ions with poly(ethylene oxide). Polymer, 1973, 14: 589

23 Aziz SB, Woo TJ, Kadir MFZ, Ahmed HM, et al. A conceptual review on polymer electrolytes and ion transport models. J Sci Adv Mater Devices, 2018, 3: 1-17

$24 \mathrm{Hu}$ J, Wang W, Yu R, et al. Solid polymer electrolyte based on ionic bond or covalent bond functionalized silica nanoparticles. RSC Adv, 2017, 7: 54986-54994

25 Meyer WH. Polymer electrolytes for lithium-ion batteries. Adv Mater, 1998, 10: 439-448

26 Pandey GP, Liu T, Hancock C, et al. Thermostable gel polymer electrolyte based on succinonitrile and ionic liquid for highperformance solid-state supercapacitors. J Power Sources, 2016, 328: $510-519$

27 Song JY, Wang YY, Wan CC. Review of gel-type polymer electrolytes for lithium-ion batteries. J Power Sources, 1999, 77: 183197

28 Feuillade G, Perche P. Ion-conductive macromolecular gels and membranes for solid lithium cells. J Appl Electrochem, 1975, 5: 63-69

29 Li W, Pang Y, Liu J, et al. A PEO-based gel polymer electrolyte for lithium ion batteries. RSC Adv, 2017, 7: 23494-23501

30 Kil EH, Choi KH, Ha HJ, et al. Imprintable, bendable, and shapeconformable polymer electrolytes for versatile-shaped lithium-ion batteries. Adv Mater, 2013, 25: 1395-1400

31 Dagousset L, Nguyen GTM, Vidal F, et al. Ionic liquids and $\gamma$ butyrolactone mixtures as electrolytes for supercapacitors operating over extended temperature ranges. RSC Adv, 2015, 5: 13095-13101

32 Dagousset L, Pognon G, Nguyen GTM, et al. Self-standing gel polymer electrolyte for improving supercapacitor thermal and electrochemical stability. J Power Sources, 2018, 391: 86-93

33 Iijima $\mathrm{T}$, Toyoguchi $\mathrm{Y}$, Eda N, et al. Quasi-solid organic electrolytes gelatinized with polymethyl-methacrylate and their applications for lithium batteries. Electrochem Soc Jpn, 1985, 53: 619-623

34 Zhao L, Huang Y, Liu B, et al. Gel polymer electrolyte basedon polymethyl methacrylate matrix composited with methacrylisobutyl-polyhedral oligomeric silsesquioxane by phase inversion method. Electrochim Acta, 2018, 278: 1-12 
35 Schwab JJ, Lichtenhan JD. Polyhedral oligomeric silsesquioxane (POSS)-based polymers. Appl Organometal Chem, 1998, 12: 707713

36 Zhang W, Camino G, Yang R. Polymer/polyhedral oligomeric silsesquioxane (POSS) nanocomposites: An overview of fire retardance. Prog Polym Sci, 2017, 67: 77-125

$37 \mathrm{Lu} \mathrm{Q}, \mathrm{Fu}$ J, Chen L, et al. Polymeric polyhedral oligomeric silsesquioxane ionic liquids based solid polymer electrolytes for lithium ion batteries. J Power Sources, 2019, 414: 31-40

38 Shang D, Fu J, Lu Q, et al. A novel polyhedral oligomeric silsesquioxane based ionic liquids (POSS-ILs) polymer electrolytes for lithium ion batteries. Solid State Ion, 2018, 319: 247-255

39 Liu B, Huang Y, Zhao L, et al. A novel non-woven fabric supported gel polymer electrolyte based on poly(methylmethacrylatepolyhedral oligomeric silsesquioxane) by phase inversion method for lithium ion batteries. J Membrane Sci, 2018, 564: 62-72

40 Nataraj SK, Yang KS, Aminabhavi TM. Polyacrylonitrile-based nanofibers-A state-of-the-art review. Prog Polym Sci, 2012, 37: 487-513

41 Hameed N, Sharp J, Nunna S, et al. Structural transformation of polyacrylonitrile fibers during stabilization and low temperature carbonization. Polym Degrad Stab, 2016, 128: 39-45

42 Hu P, Chai J, Duan Y, et al. Progress in nitrile-based polymer electrolytes for high performance lithium batteries. J Mater Chem A, 2016, 4: 10070-10083

$43 \mathrm{He}$ CF, Liu J, Li J, et al. Blending based polyacrylonitrile/poly (vinyl alcohol) membrane for rechargeable lithium ion batteries. J Membrane Sci, 2018, 560: 30-37

44 Raghavan P, Manuel J, Zhao X, et al. Preparation and electrochemical characterization of gel polymer electrolyte based on electrospun polyacrylonitrile nonwoven membranes for lithium batteries. J Power Sources, 2011, 196: 6742-6749

45 He C, Liu J, Cui J, et al. A gel polymer electrolyte based on polyacrylonitrile/organic montmorillonite membrane exhibiting dense structure for lithium ion battery. Solid State Ion, 2018, 315: 102-110

46 Liu B, Huang Y, Cao H, et al. A novel porous gel polymer electrolyte based on poly(acrylonitrile-polyhedral oligomeric silsesquioxane) with high performances for lithium-ion batteries. J Membrane Sci, 2018, 545: 140-149

47 Huang Y, Huang Y, Liu B, et al. Gel polymer electrolyte based on $\mathrm{p}$ (acrylonitrile-maleic anhydride) for lithium ion battery. Electrochim Acta, 2018, 286: 242-251

48 Prateek, Thakur VK, Gupta RK. Recent progress on ferroelectric polymer-based nanocomposites for high energy density capacitors: Synthesis, dielectric properties, and future aspects. Chem Rev, 2016, 116: 4260-4317

49 Saito Y, Takeda S, Yamagami S, et al. Effect of the morphological features of the poly(vinylidene difluoride)-based gel electrolytes on the ionic mobility for lithium secondary batteries. Macromolecules, 2019, 52: 2112-2119

50 Liu F, Hashim NA, Liu Y, et al. Progress in the production and modification of PVDF membranes. J Membrane Sci, 2011, 375: $1-27$

51 Zhu Y, Wang F, Liu L, et al. Composite of a nonwoven fabric with poly(vinylidene fluoride) as a gel membrane of high safety for lithium ion battery. Energy Environ Sci, 2013, 6: 618-624

52 Zuo X, Ma X, Wu J, et al. Self-supporting ethyl cellulose/poly (vinylidene fluoride) blended gel polymer electrolyte for $5 \mathrm{~V}$ high-voltage lithium-ion batteries. Electrochim Acta, 2018, 271:
582-590

53 Sheng J, Tong S, He Z, et al. Recent developments of cellulose materials for lithium-ion battery separators. Cellulose, 2017, 24: 4103-4122

54 Zhu $\mathrm{M}, \mathrm{Wu}$ J, Wang $\mathrm{Y}$, et al. Recent advances in gel polymer electrolyte for high-performance lithium batteries. J Energy Chem, 2019, 37: 126-142

55 Li MX, Wang XW, Yang YQ, et al. A dense cellulose-based membrane as a renewable host for gel polymer electrolyte of lithium ion batteries. J Membrane Sci, 2015, 476: 112-118

56 Zhang MY, Li MX, Chang Z, et al. A sandwich PVDF/HEC/ PVDF gel polymer electrolyte for lithium ion battery. Electrochim Acta, 2017, 245: 752-759

57 Ma X, Zuo X, Wu J, et al. Polyethylene-supported ultra-thin polyvinylidene fluoride/hydroxyethyl cellulose blended polymer electrolyte for $5 \mathrm{~V}$ high voltage lithium ion batteries. J Mater Chem A, 2018, 6: 1496-1503

58 Chen F, Ren Y, Guo J, et al. Thermo- and electro-dual responsive poly(ionic liquid) electrolyte based smart windows. Chem Commun, 2017, 53: 1595-1598

59 Dong Y, Zhang C, Wu L, et al. Self-storage: A novel family of stimuli-responsive polymer materials for optical and electrochemical switching. Macromol Rapid Commun, 2014, 35: 19431948

60 Chen T, Ferris R, Zhang J, et al. Stimulus-responsive polymer brushes on surfaces: Transduction mechanisms and applications. Prog Polymer Sci, 2010, 35: 94-112

61 Chen JK, Chang CJ. Fabrications and applications of stimulusresponsive polymer films and patterns on surfaces: A review. Materials, 2014, 7: 805-875

62 Vlad A, Singh N, Galande C, et al. Design considerations for unconventional electrochemical energy storage architectures. Adv Energy Mater, 2015, 5: 1402115

63 Choudhury NA, Sampath S, Shukla AK. Hydrogel-polymer electrolytes for electrochemical capacitors: an overview. Energy Environ Sci, 2009, 2: 55-67

64 So S, Hayward RC. Tunable upper critical solution temperature of poly $(\mathrm{N}$-isopropylacrylamide) in ionic liquids for sequential and reversible self-folding. ACS Appl Mater Interfaces, 2017, 9: 15785-15790

65 Lei Y, Zhang G, Li H. Thermal-responsive nanocomposite hydrogel based on graphene oxide-polyvinyl alcohol/poly $(N$-isopropylacrylamide). IOP Conf Ser-Mater Sci Eng, 2017, 274: 012115

66 Xia X, Yih J, D'Souza NA, et al. Swelling and mechanical behavior of poly( $\mathrm{N}$-isopropylacrylamide)/Na-montmorillonite layered silicates composite gels. Polymer, 2003, 44: 3389-3393

67 Hall CC, Zhou C, Danielsen SPO, et al. Formation of multicompartment ion gels by stepwise self-assembly of a thermoresponsive $\mathrm{ABC}$ triblock terpolymer in an ionic liquid. Macromolecules, 2016, 49: 2298-2306

68 Heskins M, Guillet JE. Solution properties of poly $(\mathrm{N}$-isopropylacrylamide). J MacroMol Sci-Part A-Chem, 1968, 2: 14411455

69 Jiang H, Roberts ME. Achieving thermally stable supercapacitors with a temperature responsive electrolyte. J Mater Sci-Mater Electron, 2019, 30: 6007-6014

70 Shi Y, Zhang Q, Zhang Y, et al. Promising and reversible electrolyte with thermal switching behavior for safer electrochemical storage devices. ACS Appl Mater Interfaces, 2018, 10: 7171-7179 
71 Zhang $\mathrm{P}$, Wang F, Yu M, et al. Two-dimensional materials for miniaturized energy storage devices: from individual devices to smart integrated systems. Chem Soc Rev, 2018, 47: 7426-7451

72 Kelly JC, Pepin M, Huber DL, et al. Reversible control of electrochemical properties using thermally-responsive polymer electrolytes. Adv Mater, 2012, 24: 886-889

73 Yang H, Liu Z, Chandran BK, et al. Self-protection of electrochemical storage devices via a thermal reversible sol-gel transition. Adv Mater, 2015, 27: 5593-5598

74 Mo F, Li H, Pei Z, et al. A smart safe rechargeable zinc ion battery based on sol-gel transition electrolytes. Sci Bull, 2018, 63: 10771086

75 Zhang P, Wang J, Sheng W, et al. Thermoswitchable on-chip microsupercapacitors: one potential self-protection solution for electronic devices. Energy Environ Sci, 2018, 11: 1717-1722

76 Macfarlane DR, Forsyth M, Howlett PC, et al. Ionic liquids and their solid-state analogues as materials for energy generation and storage. Nat Rev Mater, 2016, 1: 15005

77 MacFarlane DR, Tachikawa N, Forsyth M, et al. Energy applications of ionic liquids. Energy Environ Sci, 2014, 7: 232-250

78 Lee JH, Lee AS, Lee JC, et al. Hybrid ionogel electrolytes for high temperature lithium batteries. J Mater Chem A, 2015, 3: 22262233

79 Galiński M, Lewandowski A, Stępniak I. Ionic liquids as electrolytes. Electrochim Acta, 2006, 51: 5567-5580

80 Basile A, Hilder M, Makhlooghiazad F, et al. Ionic liquids and organic ionic plastic crystals: Advanced electrolytes for safer high performance sodium energy storage technologies. Adv Energy Mater, 2018, 8: 1703491

81 Al-Masri D, Yunis R, Hollenkamp AF, et al. A symmetrical ionic liquid/Li salt system for rapid ion transport and stable lithium electrochemistry. Chem Commun, 2018, 54: 3660-3663

82 Marr PC, Marr AC. Ionic liquid gel materials: applications in green and sustainable chemistry. Green Chem, 2016, 18: 105-128

83 Taghavikish M, Subianto S, Gu Y, et al. A poly(ionic liquid) gel electrolyte for efficient all solid electrochemical double-layer capacitor. Sci Rep, 2018, 8: 10918

84 Hazama T, Fujii K, Sakai T, et al. High-performance gel electrolytes with tetra-armed polymer network for $\mathrm{Li}$ ion batteries. J Power Sources, 2015, 286: 470-474

85 Hashimoto K, Fujii K, Nishi K, et al. Gelation mechanism of tetra-armed poly(ethylene glycol) in aprotic ionic liquid containing nonvolatile proton source, protic ionic liquid. J Phys Chem B, 2015, 119: 4795-4801

86 Ishikawa A, Sakai T, Fujii K. An ionic liquid gel with ultralow concentrations of tetra-arm polymers: Gelation kinetics and mechanical and ion-conducting properties. Polymer, 2019, 166: 38-43

87 Zhou N, Wang Y, Zhou Y, et al. Star-shaped multi-arm polymeric ionic liquid based on tetraalkylammonium cation as high performance gel electrolyte for lithium metal batteries. Electrochim Acta, 2019, 301: 284-293

88 Raut P, Liang W, Chen YM, et al. Syndiotactic polystyrene-based ionogel membranes for high temperature electrochemical applications. ACS Appl Mater Interfaces, 2017, 9: 30933-30942

89 Terech P, Weiss RG. Low molecular mass gelators of organic liquids and the properties of their gels. Chem Rev, 1997, 97: 3133-3160

90 de Loos M, Feringa BL, van Esch JH. Design and application of self-assembled low molecular weight hydrogels. Eur J Org Chem,
2005, 17: 3615-3631

91 Ye M, Wen X, Wang M, et al. Recent advances in dye-sensitized solar cells: from photoanodes, sensitizers and electrolytes to counter electrodes. Mater Today, 2015, 18: 155-162

92 Lee CP, Li CT, Ho KC. Use of organic materials in dye-sensitized solar cells. Mater Today, 2017, 20: 267-283

93 Yu Q, Yu C, Guo F, et al. A stable and efficient quasi-solid-state dye-sensitized solar cell with a low molecular weight organic gelator. Energy Environ Sci, 2012, 5: 6151-6155

94 Tao L, Huo Z, Dai S, et al. Stable quasi-solid-state dye-sensitized solar cell using ionic gel electrolyte with low molecular mass organogelator. Mater Chem Phys, 2015, 152: 62-68

95 Wang L, Huo Z, Tao L, et al. Quasi-solid-state dye-sensitized solar cell based on gel electrolyte with high gel to solution transition temperature using low molecular mass organogelator. J Photochem Photobiol A-Chem, 2016, 329: 139-145

96 Wang L, Huo Z, Tao L, et al. Effect of the self-assembled gel network formed from a low molecular mass organogelator on the electron kinetics in quasi-solid-state dye-sensitized solar cells. Sci China Mater, 2016, 59: 787-796

97 Tao L, Huo Z, Ding Y, et al. High-efficiency and stable quasisolid-state dye-sensitized solar cell based on low molecular mass organogelator electrolyte. J Mater Chem A, 2015, 3: 2344-2352

98 Tao L, Huo Z, Ding Y, et al. Gel electrolyte materials formed from a series of novel low molecular mass organogelators for stable quasi-solid-state dye-sensitized solar cells. J Mater Chem A, 2014, 2: $15921-15930$

99 Huo Z, Tao L, Dai S, et al. Quasi-solid-state dye sensitized solar cells using supramolecular gel electrolyte formed from twocomponent low molecular mass organogelators. Sci China Mater, 2015, 58: 447-454

100 Huo Z, Wang L, Tao L, et al. A supramolecular gel electrolyte formed from amide based co-gelator for quasi-solid-state dyesensitized solar cell with boosted electron kinetic processes. J Power Sources, 2017, 359: 80-87

101 Tao L, Zhang W, Wang Z, et al. Highly improved photocurrent and stability of dye-sensitized solar cell through quasi-solid-state electrolyte formed by two low molecular mass organogelators. Org Electron, 2019, 65: 179-184

102 Zhang W, Wang Z, Chen K, et al. The influences of different bicomponent supramolecular gel electrolytes on the photovoltaic performances of quasi-solid-state dye-sensitized solar cell. Mater Chem Phys, 2019, 221: 430-435

103 Venkatesan S, Lee YL. Nanofillers in the electrolytes of dye-sensitized solar cells-A short review. Coord Chem Rev, 2017, 353 : 58-112

104 Girma WM, Chen $\mathrm{CH}$, Yang $\mathrm{CH}$, et al. A low molecular mass organogelator electrolyte with $\mathrm{TiO}_{2}$ nanoparticles for stable and efficient quasi-solid-state dye sensitized solar cells. RSC Adv, 2017, 7: 7671-7678

105 May GJ, Davidson A, Monahov B. Lead batteries for utility energy storage: A review. J Energy Storage, 2018, 15: 145-157

106 Berndt D. Valve-regulated lead-acid batteries. J Power Sources, 2001, 100: 29-46

107 Lambert DWH, Greenwood PHJ, Reed MC. Advances in gelledelectrolyte technology for valve-regulated lead-acid batteries. J Power Sources, 2002, 107: 173-179

108 Hernández JC, Soria ML, González M, et al. Studies on electrolyte formulations to improve life of lead acid batteries working under partial state of charge conditions. J Power Sources, 2006, 162: 
851-863

109 Gençten M, Dönmez KB, Şahin Y, et al. Voltammetric and electrochemical impedimetric behavior of silica-based gel electrolyte for valve-regulated lead-acid battery. J Solid State Electrochem, 2014, 18: 2469-2479

110 Chen MQ, Chen HY, Shu D, et al. Effects of preparation condition and particle size distribution on fumed silica gel valveregulated lead-acid batteries performance. J Power Sources, 2008, 181: 161-171

111 Pan K, Shi G, Li A, et al. The performance of a silica-based mixed gel electrolyte in lead acid batteries. J Power Sources, 2012, 209: 262-268

112 Tantichanakul T, Chailapakul O, Tantavichet N. Gelled electrolytes for use in absorptive glass mat valve-regulated lead-acid (AGM VRLA) batteries working under 100\% depth of discharge conditions. J Power Sources, 2011, 196: 8764-8772

113 Tantichanakul $\mathrm{T}$, Chailapakul $\mathrm{O}$, Tantavichet $\mathrm{N}$. Influence of fumed silica and additives on the gel formation and performance of gel valve-regulated lead-acid batteries. J Ind Eng Chem, 2013, 19: 2085-2091

114 Gençten M. Investigation the effects of boehmite and gibbsite on the electrochemical behaviours of Gel-VRLA batteries. Int J Electrochem Sci, 2018, 11741-11751

115 Tang Z, Wang J, Mao X, et al. Investigation and application of polysiloxane-based gel electrolyte in valve-regulated lead-acid battery. J Power Sources, 2007, 168: 49-57

Acknowledgements This work was financially supported by the National Natural Science Foundation of China (21773168) and Tianjin Natural Science Foundation (16JCQNJC05000).

Author contributions $\mathrm{Yu} \mathrm{D}$ and $\mathrm{Xu} J$ proposed the topic, organized the manuscript outline and wrote the draft of the manuscript. All the coauthors contributed to the discussion and refinement of the manuscript.

Conflict of interest The authors declare that they have no conflict of interest.

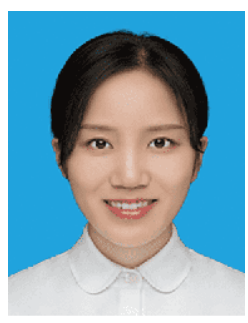

Dan Yu received her Bachelor's degree from Hainan University, China, in 2017. Currently, she is a graduate student in Tianjin University, China. Her research interest is focused on the GEs and helical polymer.

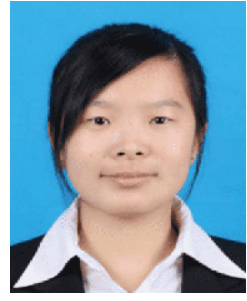

Xinyue Li received her Bachelor's degree from Hebei University of Engineering, China, in 2015. Currently, she is a graduate student in Tianjin University, China. Her research interest is focused on the nonlinear optical properties of organic self-assemblies.

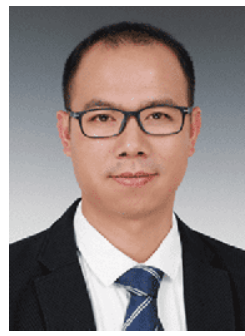

Jialiang $\mathbf{X u}$ is a professor of materials chemistry at Nankai University. He obtained his $\mathrm{PhD}$ from ICCAS in 2010 under the supervision of Prof. Yuliang $\mathrm{Li}$, and then worked as a Marie-Curie Fellow at Radboud University, Nijmegen, hosted by Prof. Alan Rowan and Prof. Theo Rasing. In 2013, he was awarded the NWO-VENI grant, with which he developed his own research profile at the interface between chemistry and physics to study the coupling between light and (supra) molecular systems. He joined the School of Chemical Engineering and Technology at Tianjin University in 2015, and relocated to the School of Materials Science and Engineering at Nankai University in 2018.

\section{凝胶电解质对电化学储能装置的安全调控}

于丹 ${ }^{1}$, 李欣悦 ${ }^{1,2}$, 徐加良 ${ }^{1,2 *}$

摘要 近几十年来, 锂离子电池、超级电容器、燃料电池等电化学 储能装置得到了蓬勃发展和广泛研究. 然而, 它们的安全问题引起 了全世界研究人员的极大关注. 因具有更高的安全性和稳定性, 在 液体和固体电解质之间具有特殊状态的凝胶电解质被认为是电化 学能量存储装置中最有希望的候选者. 在这篇综述中, 我们总结了 凝胶电解质在电化学储能装置安全性调控中应用的最新进展, 特 别关注凝胶聚合物电解质和有机小分子量凝胶电解质, 以及气相 二氧化硅基和硅氧烷基凝胶电解质. 最后, 展望了凝胶电解质研究 面临的挑战和未来的发展方向. 